\title{
Measurements of Indoor Pollutant Emissions from EPA Phase II Wood Stoves
}

Steven J. Nabinger

Andrew K. Persily

Building and Fire Research Laboratory

Katherine S. Sharpless

Stephen A. Wise

Chemical Science and Technology Laboratory

Initad States Department of Commerce logy Administration

QC I Institute of Standards and Technology

100

.456

N0. 5575

1995 



\section{Measurements of Indoor Pollutant Emissions from EPA Phase II Wood Stoves}

Steven J. Nabinger

Andrew K. Persily

Building and Fire Research Laboratory

Katherine S. Sharpless

Stephen A. Wise

Chemical Science and Technology Laboratory

February 1995

National Institute of Standards and Technology

Gaithersburg, MD 20899

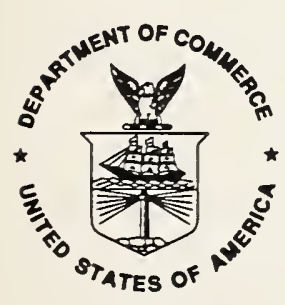

U.S. Department of Commerce

Ronald H. Brown, Secretary

Mary L. Good, Under Secretary for Technology

Prepared for:

U.S. Consumer Product Safety Commission Directorate for Health Sciences

National Institute of Standards and Technology Washington, DC 20207

Arati Prabhaker, Director 



\section{ABSTRACT}

Measurements of indoor pollutant emissions were made on four wood stoves meeting the EPA Phase II emission requirements in a $37 \mathrm{~m}^{2}\left(400 \mathrm{ft}^{2}\right)$ test house at NIST. The stoves were operated in a manner consistent with typical residential use and in accordance with the manufacturers' instructions. Three tests were conducted for each stove, with each test lasting approximately ten hours. During the tests the following quantities were monitored: combined gaseous and particulate phase concentrations of 13 individual polycyclic aromatic hydrocarbons (PAHs) averaged over the test period, including benzo[a]pyrene (B[a]P); total particulate phase PAH concentrations using a real-time monitor; mass of particulate matter below ten $\mu \mathrm{m}$ in diameter (PM10) averaged over the test period; continuous particle counts in six size ranges; continuous indoor and outdoor concentrations of carbon monoxide and carbon dioxide; building air change rates; pressures across the test house walls and in the stove flue; wind speed and direction; and indoor and outdoor air temperature and relative humidity. Based on these measurements, emission rates of total PAHs (i.e., the sum of eight individual compounds) ranged from 0.05 to $0.24 \mathrm{ng} / \mathrm{s}$ and total PAH source strengths ranged from 67 to $711 \mathrm{ng} / \mathrm{kg}$ of wood. Emission rates of $\mathrm{B}$ [a]P ranged from 0.003 to $0.028 \mathrm{ng} / \mathrm{s}$ and $\mathrm{B}$ [a]P source strengths ranged from 7 to $90 \mathrm{ng} / \mathrm{kg}$ of wood burned.

Keywords: benzo[a]pyrene, emission rates, indoor air quality, particulates, polycyclic aromatic hydrocarbons, wood stoves 


\section{DISCLAIMER STATEMENT}

Certain commercial equipment are identified in this report to describe the instrumentation used in the tests. The mention of trademarks or registered trade names of commercial products in this report does not constitute endorsement or recommendation for use by the National Institute of Standards and Technology, nor does it imply that the equipment identified are the only appropriate or best available devices for the purposes cited in this report.

This project has been funded in part with federal funds from the U.S. Consumer Product Safety Commission under interagency agreement number CPSC-IAG-93-1125. The content of the report does not necessarily reflect the views of the Commission, nor does the mention of trade names, commercial products, or organizations imply endorsement by the Commission. 


\section{TABLE OF CONTENTS}

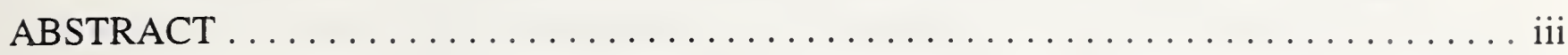

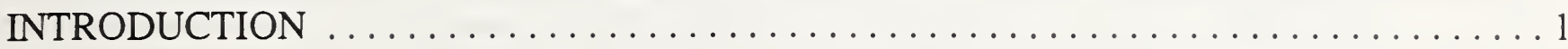

DESCRIPTION OF TEST HOUSE AND STOVES $\ldots \ldots \ldots \ldots \ldots \ldots \ldots \ldots \ldots \ldots$

MEASUREMENT PROCEDURES AND INSTRUMENTATION . . . . . . . . . . . . 3

Measurement Techniques and Instrumentation $\ldots \ldots \ldots \ldots \ldots \ldots \ldots \ldots$

Average PAH on Sorbent Tubes $\ldots \ldots \ldots \ldots \ldots \ldots \ldots \ldots \ldots \ldots \ldots \ldots \ldots \ldots \ldots \ldots$

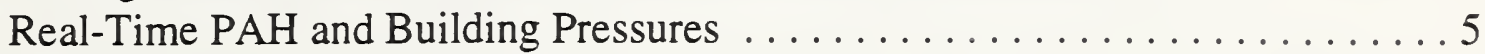

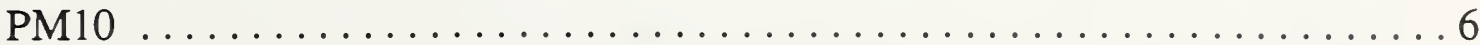

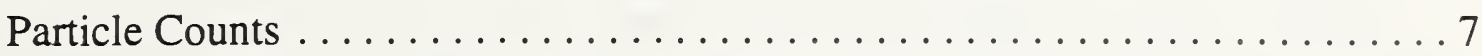

Carbon Monoxide, Carbon Dioxide and Relative Humidity . . . . . . . . . . 7

Building Air Change Rate, Temperature and Wind Speed ............ 8

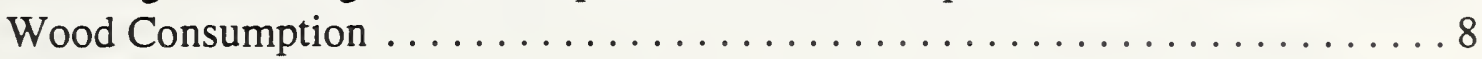

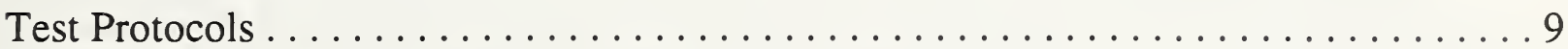

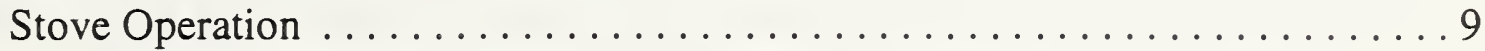

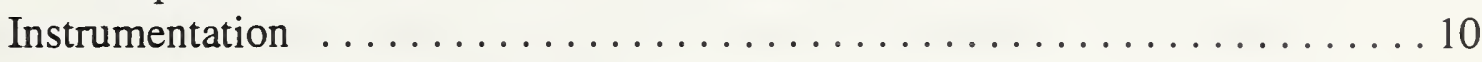

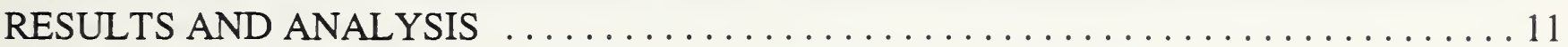



Test Results . ....................................... 12

PAH Measurements with Sorbent Tubes . . . . . . . . . . . . . . . . . . . . . . . . . 14

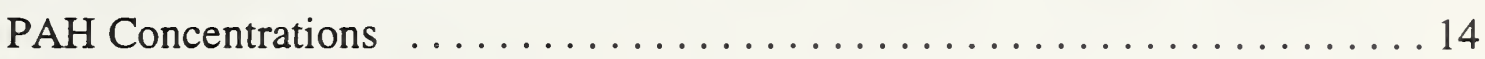



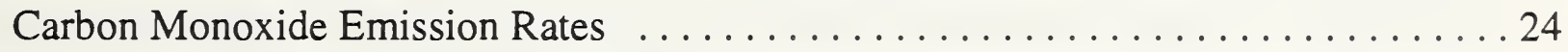

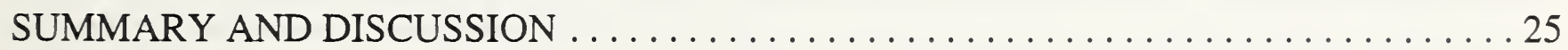



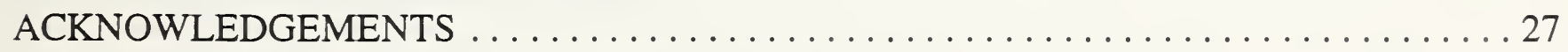

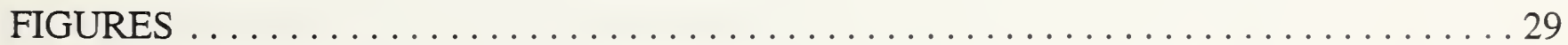

APPENDIX A STOVE OPERATION PROTOCOL ..................... 35

APPENDIX B INSTRUMENTATION PROTOCOL ....................... 37

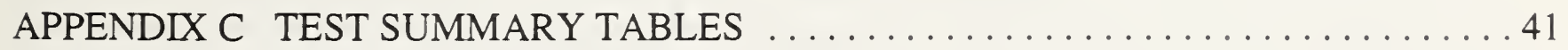

APPENDIX D PAH CONCENTRATION RESULTS $\ldots \ldots \ldots \ldots \ldots \ldots \ldots \ldots \ldots \ldots \ldots$ 



\section{INTRODUCTION}

In 1990, the U.S. Consumer Product Safety Commission (CPSC) staff completed a preliminary assessment of the risk of cancer from benzo[a]pyrene (B[a]P) and other polycyclic aromatic hydrocarbons (PAHs) associated with indoor wood stove emissions. While the CPSC risk assessment was in progress, the U.S. Environmental Protection Agency (EPA) set requirements to reduce particulate emissions into the outdoor air from wood stoves. The final requirements are referred to as the EPA Phase II requirements. Because of the changes in wood stove design made to comply with the Phase II requirements, CPSC is updating their cancer risk assessment. Current indoor PAH emission rate data are required by CPSC in order to perform this risk assessment. This report presents the results of indoor PAH emission rate measurements performed on four wood stoves complying with the EPA Phase II requirements.

There have been several studies of the impact of wood stove operation on the indoor concentrations of PAHs and other contaminants (Offermann 1994; Knight et al. 1986; Knight and Humphreys 1985; Traynor et al. 1987). Based on the stove designs at the time, these studies concentrated on the difference between airtight, non-airtight and catalytic stoves. Some of these studies were designed to assess human exposure to indoor PAHs from a variety of sources, including the outdoor air, fireplaces, wood stoves, cigarette smoke and combustion appliances (Offermann 1994; Sheldon et al. 1993a). The study presented in this report is concerned only with indoor emissions from wood stoves meeting the Phase II requirements. The primary objective of this study is to determine the PAH emission rates from these stoves with specific emphasis on $\mathrm{B}[\mathrm{a}] \mathrm{P}$ emissions.

In order to assess PAH emission rates and source strengths from the wood stoves tested in this study, the stoves were installed in a small test house and operated in a manner consistent with typical residential use and manufacturers' instructions. Each test consisted of about ten hours of stove operation, during which a variety of parameters were measured including indoor PAH concentrations and building air change rates. Based on the data collected, a single-zone mass balance analysis was used to determine PAH emission rates in units of nanograms emitted per second and source strengths in nanograms emitted per kilogram of wood burned. These emission rates and source strengths were determined for the sum of eight PAH compounds and for $\mathrm{B}[\mathrm{a}] \mathrm{P}$. The PAH concentrations, emission rates and source strengths were determined for the gaseous and particulate phases combined.

\section{DESCRIPTION OF TEST HOUSE AND STOVES}

The tests were performed in a single-room test house located on the NIST campus (Burch et al. 1982). The test house has a floor area of $37 \mathrm{~m}^{2}\left(400 \mathrm{ft}^{2}\right)$ and contains no interior partitions.

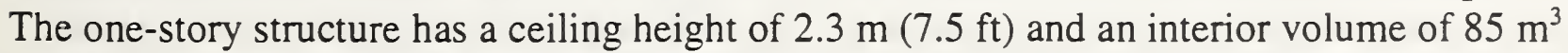
$\left(3000 \mathrm{ft}^{3}\right)$. It has uninsulated wood frame walls, an exterior facade of paneled wood, and an interior finish of painted gypsum board. The foundation is slab on grade, with an unpainted concrete floor. The house has an uninsulated, ventilated attic and an asphalt-shingled, pitched roof. There are two double-hung windows with storm windows on the north and south walls and a metal exterior door filled with perlite insulation at the north end of the east wall. The house has a $4.1 \mathrm{~kW}(14,000 \mathrm{Btu} / \mathrm{h})$ electric-resistance, forced-air heating unit and a $3.8 \mathrm{~kW}$ 
$(13,000 \mathrm{Btu} / \mathrm{h})$ air conditioner. A schematic elevation of the test house is shown in Figure 1, showing the dimensions of the structure and the stove installation.

The airtightness of the house was determined with a fan pressurization test conducted according to ASTM Standard E779-87 (1992). Based on this test, the building air change rate at $50 \mathrm{~Pa}$ is 6.5 air changes per hour (ach), and the effective leakage area at $4 \mathrm{~Pa}$ is $130 \mathrm{~cm}^{2}\left(20 \mathrm{in}^{2}\right)$. Based on the single-zone infiltration model in the ASHRAE Fundamentals Handbook (ASHRAE 1993), these results correspond to an air infiltration rate of 0.3 ach under typical winter conditions. As discussed later in this report, the air infiltration rates of the test house were monitored during the stove tests using the tracer gas decay technique.

Four wood stoves were tested in this study. Two were made of cast iron, and the other two of welded steel. One of each pair had a catalytic converter. Based on the small size of the test house, stoves with the minimum heat output rating in each of the four categories were selected for the tests. In this report, the four stoves are referred to as A, B, C and D as follows:
A Cast iron, catalytic: $3.2-9.0 \mathrm{~kW}(10,900-30,600 \mathrm{Btu} / \mathrm{h})$,
B Cast iron, non-catalytic: $2.6-6.6 \mathrm{~kW}(8,700-22,500 \mathrm{Btu} / \mathrm{h})$,
C Welded steel, non-catalytic: $3.1-13.0 \mathrm{~kW}(10,500-44,500 \mathrm{Btu} / \mathrm{h})$,
D Welded steel, catalytic: $3.0-7.9 \mathrm{~kW}(10,100-26,900 \mathrm{Btu} / \mathrm{h})$.

The stove manufacturers provide a heating capacity for each stove in terms of the floor area that it can heat. These ratings are approximate in that they do not account for climate or the thermal characteristics of the house being heated. Stoves A and B are rated to heat up to $110 \mathrm{~m}^{2}$ $\left(1200 \mathrm{ft}^{2}\right)$, Stove $C$ is rated to heat $90 \mathrm{~m}^{2}\left(1000 \mathrm{ft}^{2}\right)$, and Stove D is rated at $200 \mathrm{~m}^{2}\left(2200 \mathrm{ft}^{2}\right)$. Stoves A, B and C rely on radiant heating, while Stove D has a fan to heat the room through convection.

The smoke emission ratings of Stoves A, B, C and D were 3.6, 2.9, 6.1 and $3.4 \mathrm{~g} / \mathrm{h}$ respectively. Their average efficiency ratings were $72 \%, 63 \%, 63 \%$ and $72 \%$. Stove A had a sliding draft control, to control the flow of room air into the stove, and a damper bypass control, to allow the flue gases to bypass the catalytic converter. Stove B had a sliding combustion air inlet control and a spin draft control, both used to control the flow of room air into the stove. Stove $\mathrm{C}$ had only a single combustion air intake control, making it more difficult to control the stove temperature. Stove D had two sliding combustion air inlet controls and a catalytic converter bypass control.

Before testing, each stove went through a break-in process wherein five progressively larger fires were burned to cure the high-temperature stove paint. A stove thermometer was attached $10 \mathrm{~cm}$ ( $4 \mathrm{in}$ ) up the flue pipe from the stove top to monitor the stove temperature during the break-in process and during the subsequent testing. The first break-in fire lasted one hour at a stove temperature of $200^{\circ} \mathrm{C}\left(400^{\circ} \mathrm{F}\right)$. The following four fires were made progressively hotter, the last of which burned at a stove temperature above $400^{\circ} \mathrm{C}\left(750^{\circ} \mathrm{F}\right)$ for at least one hour. The stoves were allowed to cool to room temperature between each fire. The wood used in the tests was oak that had been seasoned for approximately one year. 


\section{MEASUREMENT PROCEDURES AND INSTRUMENTATION}

This section describes the measurement procedures and instrumentation used in the wood stove tests. The measurement techniques and instrumentation are presented first, followed by a discussion of the test protocols.

\section{Measurement Techniques and Instrumentation}

This section describes the measurement techniques and instrumentation used in the wood stove tests. As mentioned earlier, the following quantities were monitored during the tests: combined gaseous and particulate phase concentrations of individual PAHs averaged over the test period, including benzo[a]pyrene $(\mathrm{B}[\mathrm{a}] \mathrm{P})$; total particulate phase $\mathrm{PAH}$ concentrations using a real-time monitor; mass of particulate matter below $10 \mu \mathrm{m}$ in diameter (PM10) averaged over the test period; continuous particle counts in six size ranges; indoor and outdoor concentrations of carbon monoxide and carbon dioxide; building air change rates; pressure differences across the walls of the test house and pressure in the stove flue; wind speed and direction; and indoor and outdoor air temperature and relative humidity. Figure 2 is a schematic floor plan of the test house, showing the instrumentation systems and the sampling locations.

\section{Average PAH on Sorbent Tubes}

Average PAH concentrations were measured by sampling air using a sorbent tube with a quartz filter and analyzing an extract from the sorbent and filter with liquid chromatography (LC) and fluorescence spectrometry (FS). Although the tubes contained both XAD-2 sorbent and a quartz filter, they are referred to simply as sorbent tubes in this report. Six air samples were collected during each test, three during a long sampling period and three during a short sampling period. The long period began just before the fire was started in the wood stove, and the short period began after the second loading of wood into the stove. Both sampling periods ended at the same time, roughly $10 \mathrm{~h}$ after the fire was started. Therefore, the long sample was collected over about $10 \mathrm{~h}$ and the short sample over about $8 \mathrm{~h}$. Two short samples and two long samples were collected indoors, about $1.5 \mathrm{~m}(5 \mathrm{ft})$ above the floor at the locations shown in Figure 2. For each test, a short and a long sample were also collected outdoors at a distance of about $36 \mathrm{~m} \mathrm{(120}$ ft) from the test house.

The sorbent tubes were manufactured by Supelco (Bellefonte, PA), and are shown schematically in Figure 3. The glass tubes had an overall length of $12.5 \mathrm{~cm}(5 \mathrm{in})$, a $2.54-\mathrm{cm}$ (1-in) outside diameter (OD) at the inlet and a $0.95-\mathrm{cm}(3 / 8$-in) OD at the suction end. The tubes were packed with two 2.5 -g beds of XAD-2 sorbent material separated by a polyurethane foam (PUF) plug. PUF was also placed at each end of the tube to retain the XAD-2 sorbent during handling and sampling. A quartz fiber filter was placed outside the PUF plug at the air inlet end of the tube to retain particulate phase PAHs. The sorbent tubes were received from the manufacturer wrapped in aluminum foil and inside screw-capped, colorless glass jars. The tubes were pre-cleaned by the manufacturer using EPA Method 0010. This method consists of four 22 -h periods of Soxhlet extraction using water, methyl alcohol, and then methylene chloride twice. In addition, prior to sampling, NIST pre-cleaned the tubes in Soxhlet extractors for $24 \mathrm{~h}$ using methylene chloride. The tubes were then wrapped in clean aluminum foil, replaced in the glass jars and stored in a freezer at $-23^{\circ} \mathrm{C}\left(-9.4^{\circ} \mathrm{F}\right)$. 
Air samples were collected on the sorbent tubes using Gilian AirCon-2 air sample systems (Caldwell, NJ). These systems consist of a high-volume, positive-displacement sample pump, a telescopic mast and a sample hose. The pump is capable of maintaining constant flow over a range of $2-20 \mathrm{~L} / \mathrm{min}$ (liters per minute), and the sample hose has a support tip to mount the sample at the top of the mast, which can be extended up to $1.5 \mathrm{~m}(5 \mathrm{ft})$. The airflow is set with an external flow knob, and the nominal flow rate is indicated on a built-in rotameter. Most of the test samples were collected with the pumps operating at $10 \mathrm{~L} / \mathrm{min}$. However, airflow rates of 15 and $20 \mathrm{~L} / \mathrm{min}$ were used in some of the early tests in order to determine the limits of detection and to evaluate breakthrough. For a 10-hour test, with a sample airflow rate of $10 \mathrm{~L} / \mathrm{min}$, the lower limit of detection of the individual PAHs ranged from $0.003 \mathrm{ng} / \mathrm{m}^{3}$ for anthracene to $0.05 \mathrm{ng} / \mathrm{m}^{3}$ for indeno [1,2,3-cd]pyrene. Under these test conditions, the lower limit of detection for benzo[a]pyrene was $0.01 \mathrm{ng} / \mathrm{m}^{3}$.

After the samples were collected, the sorbent tubes were refrigerated at $4{ }^{\circ} \mathrm{C}\left(39^{\circ} \mathrm{F}\right)$ prior to extraction. At the time of extraction, one $\mathrm{mL}$ of internal standard solution in acetonitrile (described below) was added to each tube. All of the solvent was absorbed by the packing material. Tubes were Soxhlet extracted with methylene chloride for $20 \mathrm{~h}$. The solvent was then evaporated, and $300 \mu \mathrm{L}$ of hexane were added to yield approximately $400 \mu \mathrm{L}$ of a $75 \%$ hexane/25\% methylene chloride solution. The extract was pipetted onto an amino Sep-Pak solid-phase extraction cartridge (Waters, Bedford, MA) that had been pre-cleaned with a $2 \%$ methylene chloride $/ 98 \%$ hexane solution. Analytes were eluted from the cartridge using two $10-\mathrm{mL}$ portions of this methylene chloride/hexane solution. The solvent was evaporated and exchanged to acetonitrile; final sample volumes were approximately $300 \mu \mathrm{L}$. Samples were not allowed to evaporate to dryness during either stage of evaporation. Samples were placed in glass inserts in screw-capped amber autosampler vials, and were stored under refrigeration until analysis.

SRM 1597 (NIST, Standard Reference Material Program, Gaithersburg, MD), Complex Mixture of Polycyclic Aromatic Hydrocarbons from Coal Tar, was used as a quality control (QC) sample. A portion of the SRM, which is in toluene, was combined with a concentrated internal standard solution in hexane. The mixture was pipetted onto a pre-cleaned amino Sep-Pak cartridge, and analytes were eluted with $2 \%$ methylene chloride/ $98 \%$ hexane. The solvent was evaporated and exchanged to acetonitrile. The QC solution was stored in a volumetric flask in a refrigerator, and portions were withdrawn daily for analysis with the wood stove emission samples.

The liquid chromatograph (LC) was equipped with a Hypersil PAH analytical column (Serial No. 034552G, Keystone Scientific, Bellefonte, PA) which was held at $27^{\circ} \mathrm{C}\left(80^{\circ} \mathrm{F}\right)$ by a circulating water bath. A $0.5-\mathrm{mm}$ stainless steel in-line frit protected the analytical column. Solvent A was $50 \%$ acetonitrile/50\% water; solvent B was acetonitrile. The LC method consisted of a linear gradient that began with $100 \% \mathrm{~A}$ and went to $100 \% \mathrm{~B}$ in $50 \mathrm{~min}$. The system was then returned to initial conditions over $5 \mathrm{~min}$ and was re-equilibrated for $10 \mathrm{~min}$. The flow rate was $1.5 \mathrm{~mL} / \mathrm{min}$. A programmable fluorescence spectrometer (FS) was used to measure the PAHs using the wavelength program shown in Table 1.

The liquid chromatograph-fluorescence spectrometer (LC/FS) system was calibrated using eight calibration solutions. A series of four low-concentration and four high-concentration 
calibration solutions, covering analyte ranges observed in six preliminary samples obtained during wood stove burns in the test house, were prepared from SRM 1647c (NIST, Standard Reference Material Program, Gaithersburg, MD), Priority Pollutants in Acetonitrile. Perylene, which is not included in SRM $1647 \mathrm{c}$, was added to the low series of calibrants. Naphthalene- $\mathrm{d}_{8}$ (Merck, Rahway, NJ, Lot 2068F), phenanthrene- $d_{10}$ (Merck, Sharp, and Dohme [MSD], Rahway, $\mathrm{NJ}$, Lot $109 \mathrm{~K}$ ), fluoranthene- $\mathrm{d}_{10}$ (MSD, Lot 2389J), and perylene- $\mathrm{d}_{12}$ (MSD, Lot 2310F) were used as internal standards.

Table 1 Programmed wavelength changes for the fluorescence detector and measured analytes

\begin{tabular}{|c|c|c|c|}
\hline & $\frac{\text { Excitation }}{\text { Wavelenoth }(\mathrm{nm})}$ & $\frac{\text { Emission }}{\text { Wavelength }(\mathrm{nm})}$ & Analvtes \\
\hline $11 \mathrm{me}(\mathrm{min})$ & & & Amanyes \\
\hline 5 & 280 & 340 & $\begin{array}{l}\text { Naphthalene- } d_{8} \\
\text { Naphthalene }\end{array}$ \\
\hline 11.9 & 249 & 362 & $\begin{array}{l}\text { Phenanthrene- } d_{10} \\
\text { Phenanthrene }\end{array}$ \\
\hline 17 & 250 & 400 & Anthracene \\
\hline 19 & 285 & 450 & $\begin{array}{l}\text { Fluoranthene- } d_{10} \\
\text { Fluoranthene }\end{array}$ \\
\hline 22 & 333 & 390 & Pyrene \\
\hline 25 & 285 & 385 & Benz[a]anthracene \\
\hline 30.9 & 263 & 358 & Chrysene \\
\hline 34.5 & 406 & 440 & $\begin{array}{l}\text { Perylene- } d_{12} \\
\text { Perylene }\end{array}$ \\
\hline 39.5 & 296 & 405 & $\begin{array}{l}\text { Benzo[k]fluoranthene } \\
\text { Benzo[a]pyrene } \\
\text { Dibenz[a,h]anthracene } \\
\text { Benzo[ghi]perylene }\end{array}$ \\
\hline 50.2 & 300 & 500 & Indeno[1,2,3-cd]pyrene \\
\hline
\end{tabular}

Real-Time PAH and Building Pressures

A personal computer (PC) was used to monitor and record total polycyclic aromatic hydrocarbon concentrations and pressure differences across the test building walls and in the stove flue. This PC-based data acquisition system recorded voltages from the PAH monitor and pressure sensors through an interface box fabricated at NIST. The PAH measurements were made using an EcoChem Model PAS 1000i, Realtime Polycyclic Aromatic Hydrocarbon Analyzer for Combustion Aerosols (EcoChem, West Hills, CA). The analyzer senses PAHs with a photoelectric aerosol sensor that works on the principle of photoionization of carbon aerosols in the air sample using UV light. By choosing a specific wavelength of UV light at a low intensity, only carbon particles with PAHs on the surface emit electrons. The electrons are removed and the positively-charged particles are collected inside an electrometer where the charge is measured. The concentration of the PAHs in the air sample is proportional to the signal resulting from the measured charge. While PAHs exist in both particulate and vapor phases, the EcoChem 
monitor detects only those PAHs in the particulate phase and does not differentiate between PAH species. The monitor was calibrated by the manufacturer using the average of several calibration curves from PAH sources such as combustion engines and oil burners. Assuming this curve is also representative of wood stove emissions, the lower limit of detection of the monitor is 10 $\mathrm{ng} / \mathrm{m}^{3}$ and the resolution is $7 \mathrm{ng} / \mathrm{m}^{3}$.

The pressure differences across the exterior walls, and between the indoors and the interior of the stove flue, were measured using differential pressure transducers. Each of the transducers transmitted a 0-5 VDC signal to the data acquisition system. The transducers were calibrated by the manufacturer and zeroed after installation in the test house. The transducers used on the walls have a range of -25 to $25 \mathrm{~Pa}$ ( -0.1 to 0.1 in of water), and the flue transducer has a range of -62.5 to $62.5 \mathrm{~Pa}(-0.25$ to 0.25 in of water). The pressure transducers have an accuracy of $1 \%$ full scale. The wall pressure differences were measured $1.5 \mathrm{~m}(5 \mathrm{ft})$ above the floor and horizontally centered in each of the four walls. The flue transducer was installed

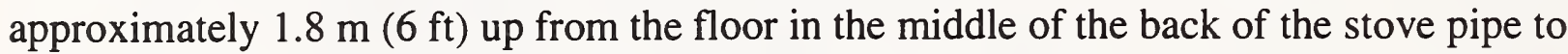
measure the pressure difference between the flue and the indoors. A negative pressure on the wall transducers corresponded to a lower pressure in the house than outside the house. A negative pressure on the flue transducer corresponded to a lower pressure in the flue relative to the pressure inside the house.

The data acquisition system monitored the PAH analyzer and differential pressure sensor output voltages every $5 \mathrm{~s}$. At the end of $10 \mathrm{~min}$, the measurements from the 5 channels were averaged and written to an ASCII file.

\section{PM10}

PM10 concentrations were measured using two aerosol samplers, each consisting of a particle impactor and a pumping unit. The pumping units contain a pump, a mass flow controller, a flow control circuit, and a timer. Two impactors can be connected to each pumping unit. The impactors are made of aluminum and consist of the inlet, the impaction stage, the body and the base. The impactors were configured to collect particles with aerodynamic diameters less than $10 \mu \mathrm{m}$. During sample collection, air flows into the inlet, through the nozzle, around the impaction plate, through the body and out the base. A 37-mm Teflon filter was placed in the base to collect the particles that flow around the impaction plate.

The PM10 sample pumps were calibrated prior to the wood stove tests with a bubble flow calibration device having an accuracy of $2 \%$ of the reading. During the tests, the pumps were set at $10 \mathrm{~L} / \mathrm{min}$, based on the calibrations. This airflow rate was verified during the tests by measuring and recording the voltage output of the mass flow meters. Long and short samples of the test house air and the outdoor air were collected. The long samples were started before the fire and were about $10 \mathrm{~h}$ in duration. The short samples were collected over about $8 \mathrm{~h}$ and were started after the second loading of wood. Two impactors were set up in the test house and two at an outdoor location. The two indoor impactors were located near the north wall sample point, as

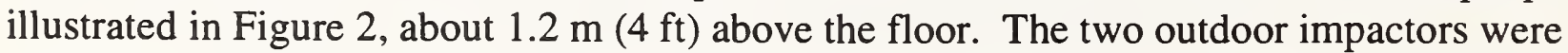
located about $36 \mathrm{~m}$ ( $120 \mathrm{ft})$ south west of the house at a height of about $1.5 \mathrm{~m}(5 \mathrm{ft})$ above the ground. The filters were sent to a commercial laboratory to gravimetrically determine the particulate mass collected during the test. 


\section{Particle Counts}

Particle counts were measured in six size ranges with a microprocessor-based airborne particle counter. The particles were sampled at the single indoor location shown in Figure 2. The particle counter incorporates an elliptical mirror system and employs the principle of wideangle light scattering. When particles enter the particle sensing zone of the elliptical mirror, they scatter light to a photomultiplier tube, which in turn detects the light and converts it to an electrical signal. The magnitude of the signal is proportional to the size of the particle scattering the light. The system has a size sensitivity of $0.3 \mu \mathrm{m}$ and a resolution of $0.02 \mu \mathrm{m}$. The counter was calibrated by the manufacturer prior to the wood stove tests and performs an automatic field calibration between each sample period. The six measured particle ranges were: $0.3-0.5 \mu \mathrm{m}$, 0.5-0.7 $\mu \mathrm{m}, 0.7-1.0 \mu \mathrm{m}, 1-5 \mu \mathrm{m}, 5-10 \mu \mathrm{m}$, and greater than $10 \mu \mathrm{m}$. The particle counter was programmed to count particles for $9 \mathrm{~min}$ and then delay for $1 \mathrm{~min}$ while the total particle counts of the six ranges were recorded. The particle counts were recorded in an ASCII file by a personal computer through an RS-232 serial port link between the computer and the particle counter. The recorded particle counts were converted to concentrations in units of number of particles per $\mathrm{m}^{3}$ of air for each of the six size ranges. Hourly averages of these concentrations were then calculated.

Carbon Monoxide, Carbon Dioxide and Relative Humidity

Carbon monoxide $(\mathrm{CO})$ and carbon dioxide $\left(\mathrm{CO}_{2}\right)$ concentrations and percent relative humidity (RH) were monitored and recorded by another computer-based data acquisition system. The system employed a computer-controlled multiposition valve to switch between sample locations and infrared absorption analyzers to monitor the $\mathrm{CO}$ and $\mathrm{CO}_{2}$ concentrations. The $\mathrm{CO}$ monitor has a range of $0-50$ parts per million (ppm) and is accurate to within $0.1 \mathrm{ppm}$. The $\mathrm{CO}_{2}$ monitor has a range of $0-2500 \mathrm{ppm}$ and is accurate to within $0.5 \%$ of full scale. The $\mathrm{CO}$ and $\mathrm{CO}_{2}$ instruments were calibrated between each test, and the calibrations were checked during each test. The relative humidity sensors are bulk polymer resistance sensors with an accuracy of $3 \%$ of the reading. The relative humidity sensors were calibrated by the manufacturer and compared to other NIST-calibrated RH sensors.

$\mathrm{CO}$ and $\mathrm{CO}_{2}$ concentrations were measured at the indoor north, south and west sampling locations, and at the outdoor north and west locations shown in Figure 2. The concentration monitors have continuous outputs, which were recorded at the end of each minute. Two consecutive one-minute measurements were made at each location and were recorded in an ASCII file. The relative humidity was measured at the north and south indoor sample locations. The outdoor $\mathrm{RH}$ was measured below the eave of the roof at the east end of the north wall. The average $\mathrm{RH}$ at each location was recorded in a ASCII file every $10 \mathrm{~min}$. The $\mathrm{CO} / \mathrm{CO}_{2} / \mathrm{RH}$ system was generally run $24 \mathrm{~h}$ each day while the stoves were being tested. Hourly averages of the concentrations and $\mathrm{RH}$ were calculated from the recorded data. 
Building air change rates (ach) were measured with an automated tracer gas decay system. This computer-based system consists of a tracer gas monitor and subsystems for tracer gas injection and air sampling. The system was also used to monitor indoor and outdoor temperatures, wind speed and wind direction. Sulfur hexafluoride $\left(\mathrm{SF}_{6}\right)$ was the tracer gas used in the tests. The $\mathrm{SF}_{6}$ concentration was monitored with a gas chromatograph equipped with an electron capture detector. The system was calibrated before each test, and the calibration was checked during each test. The electron capture detector of the system was capable of determining $\mathrm{SF}_{6}$ concentrations over a range of approximately 10 to $250 \mathrm{ppb}$ with an accuracy of approximately $2 \%$. The tracer gas injection subsystem employed a computer-controlled solenoid to inject $\mathrm{SF}_{6}$ into the distribution duct of the forced-air furnace. The furnace fan was used to mix and distribute the tracer gas within the house. The air sampling subsystem consists of sample pumps used to pull air from the sample locations and a computer-controlled multiposition valve to switch between sample locations. The indoor and outdoor tracer gas sample locations were identical to those of the $\mathrm{CO}$ and $\mathrm{CO}_{2}$ monitoring systems. The uncertainty of the measured air change rates is approximately $10 \%$ of the value.

The indoor and outdoor temperatures were measured with thermistors having an uncertainty of about $0.4^{\circ} \mathrm{C}\left(0.7^{\circ} \mathrm{F}\right)$. An anemometer was installed on the west exterior wall, approximately $2.0 \mathrm{~m}(6.6 \mathrm{ft})$ above the crest of the roof, to measure wind speed and direction. Interior temperatures were measured about $1.5 \mathrm{~m}(6 \mathrm{ft})$ above the floor and about $0.3 \mathrm{~m}(1 \mathrm{ft})$ out from the center of each wall as illustrated in Figure 2. The outdoor temperature was measured below the eave of the roof at the west end of the north wall. The temperature, wind speed and direction were measured every minute and recorded as hourly averages.

\section{Wood Consumption}

Before each test, approximately 12 pieces of wood were numbered, and the weight and moisture content (MC) of each piece was measured and recorded. The moisture content was measured in four places on each piece of wood using a moisture meter with a measurement range of $4.5 \%$ to $60 \% \mathrm{MC}$ on a dry basis and a resolution of $0.1 \% \mathrm{MC}$. The wood scale has a range from $0-23 \mathrm{~kg}(0-50 \mathrm{lbs})$ and a resolution of $0.05 \mathrm{~kg}(0.1 \mathrm{lb})$. When wood was added to the stove, the time and identification numbers of the wood pieces were recorded. 
Test Protocols

Two protocols were developed to insure consistent test procedures and data collection during stove tests. One protocol, titled Stove Operation Protocol, was developed for operating the wood stoves and is presented in Appendix A. The other, titled Instrumentation Protocol, was developed for the test equipment and is presented in Appendix B. This section describes both protocols.

\section{Stove Operation}

The Stove Operation Protocol describes the preparation of the test house, wood and stove prior to the tests, and the operation of the stove during the test. It also describes the "shut down" process at the end of the test and the procedure for cleaning the house between tests. On non-test days, the thermostat in the test house was set at $21^{\circ} \mathrm{C}\left(70^{\circ} \mathrm{F}\right)$. On the day before a test, one piece of wood was weighed and its moisture content was measured. The piece of wood was then split for kindling. Just prior to the test, 12 additional pieces of wood were numbered and weighed, and the moisture content of each piece was measured and recorded. The furnace thermostat was set to $15^{\circ} \mathrm{C}\left(60^{\circ} \mathrm{F}\right)$ and the fan was set for continuous operation. At the beginning of the test, the stove combustion air vent(s) and catalytic converter bypass damper (if present) were opened and three fire starters were placed in the stove with kindling loosely stacked on top. The fire starters were then lit, the stove door was closed, and the time and room temperature were recorded. The fire starters, approximately $2.5 \mathrm{~cm}^{2} \times 1 \mathrm{~cm}\left(1 \mathrm{in}^{2} \times 3 / 8\right.$ in), were made of $10 \%$ recycled wood and unspecified substances designed to light easily and stay lit, to simplify the starting of wood fires. After the kindling was burning well, the stove door was opened about $1.5 \mathrm{~cm}(1 / 2 \mathrm{in})$ for $10 \mathrm{~s}$, then slowly opened completely. This door opening procedure was employed to prevent smoke from entering the room from the stove due to opening the door too quickly. With the door open, two or three pieces of wood were added to fill the stove, the door was closed, and the numbers of the wood pieces were recorded along with the time, stove temperature and the room temperature. When the stove temperature reached $200{ }^{\circ} \mathrm{C}$ $\left(400^{\circ} \mathrm{F}\right)$, the vents were closed partially to keep the house temperature between 21 and $27^{\circ} \mathrm{C}$ $\left(70\right.$ and $80^{\circ} \mathrm{F}$ ). If the stove had a catalytic converter, it was also closed at this time. Once a base of coals was formed and the first load of wood was burned down to roughly one-quarter of the interior volume of the stove, the catalytic converter and the vents were opened, the door was opened about $1.5 \mathrm{~cm}(1 / 2 \mathrm{in})$ for $10 \mathrm{~s}$, then opened all the way, and the stove was reloaded to full capacity. After reloading, the door was closed and the numbers of the loaded wood pieces recorded. The vents and the catalytic converter (if present) were closed when the stove temperature reached $200^{\circ} \mathrm{C}\left(400{ }^{\circ} \mathrm{F}\right)$. The reloading process continued throughout the test. When the test was over, the vents and catalytic converter were opened fully.

During the test, the vents of the stove were closed if the room temperature rose above $27^{\circ} \mathrm{C}\left(80^{\circ} \mathrm{F}\right)$ and opened if the room temperature went below $21^{\circ} \mathrm{C}\left(70^{\circ} \mathrm{F}\right)$. Also, if the stove temperature dropped below $150^{\circ} \mathrm{C}\left(350^{\circ} \mathrm{F}\right)$ and had a catalytic converter, the converter was opened. If the stove rose above $200^{\circ} \mathrm{C}\left(400^{\circ} \mathrm{F}\right)$, the converter was closed. When the stove vents or catalytic converter were adjusted, the stove and room temperature, along with the adjustment, were recorded. On the day after a test, the stove's ash bin was emptied, leaving a bed of ashes about $2.5 \mathrm{~cm}$ ( 1 in) thick, and the house floor was swept and wet-mopped. 


\section{Instrumentation}

The Instrumentation Protocol describes the preparation of the test equipment and data acquisition systems, the equipment operation and air sampling procedures during the test, and the procedure for equipment shut-down after the test. Tasks related to the test equipment between tests are also described. The protocol describes the procedure for starting and ending the long and short PM10 and PAH samples, mid-morning and mid-afternoon equipment checks, post-test activity and instrumentation checks, and calibrations on non-test days. At the beginning of a test, the operational status of each piece of equipment was checked and recorded. The tracer gas decay system operation was checked and critical parameters were recorded. Sample lines and pumps were also checked to insure they were connected and functioning properly. The indoor and outdoor $\mathrm{SF}_{6}, \mathrm{CO}$ and $\mathrm{CO}_{2}$ concentrations were examined to verify that they were within reasonable ranges. Next, the PAH concentrations and wall/flue pressures were examined to verify that the real-time PAH analyzer and pressure transducers were functioning properly. The operation of the particle counter system was also checked.

After these equipment checks, the PM10 and PAH sample pumps were started and the airflow rates were checked. After proper operation was verified and the PAH sample stands were set up, the pumps were turned off and the long PAH sample tubes and PM10 filters were labeled. The long PAH sample tubes were then connected to the sample lines, and the particulate filters were put in the PM10 impactors. The long PAH sample pumps and the PM10 pumps were then started, and the start times recorded along with the timer readings from the mass flow controller and elapsed time indicators in the PM10 pumping unit boxes. After the second loading of the stove with wood, the short PAH sample tubes and PM10 filters were labelled and installed, the short sample pumps were started, and the start times were recorded.

Three to four hours into each test, an equipment performance check was performed. The tracer gas system base and peak frequencies were checked and recorded, and the concentrations of selected $\mathrm{SF}_{6}$ calibration gases were measured and recorded. The indoor and outdoor $\mathrm{CO}$ and $\mathrm{CO}_{2}$ concentrations were checked to insure they were in a reasonable range, and the concentrations of selected calibration gases were measured and recorded. The PAH levels and wall pressures were checked to see that they were within expected ranges, and the particle counter display was checked to insure that the counts were being written to the personal computer. The inspection also involved checking and recording the DC voltages from the PM10 pumps and the airflow rates of the PAH pumps. About $3 \mathrm{~h}$ before the end of the test, another equipment check was performed which included all the tasks of the previous equipment check, with the exception that the $\mathrm{SF}_{6}, \mathrm{CO}$ and $\mathrm{CO}_{2}$ calibration gases were not sampled.

When the test was over, the PAH and PM10 pumps were turned off, the samples were collected, and the sample end-times were recorded. A post-test inspection of the operation of the equipment was then performed.

On non-test days, the tracer gas decay system was thoroughly checked to see that the sample injection time and the time the sample took to elute from the gas chromatographic column had not changed. The $\mathrm{SF}_{6}$ detector was then calibrated. The pressure transducers were also rechecked and zeroed if needed, and the impactor pumping units were recalibrated. 


\section{RESULTS AND ANALYSIS}

This section presents the results of the wood stove tests and the analysis of the measured data. The various tests are described first in terms of their duration, temperature conditions and fuel consumption. A table containing the detailed results of one test is presented. Similar tables for all tests are contained in Appendix C. The results of the PAH concentration measurements based on the sorbent tubes are then given. The analysis of these concentrations to determine indoor PAH emission rates and source strengths is described and these results are presented. Similarly, indoor $\mathrm{CO}$ emission rates and source strengths were determined and these results are presented.

\section{Summary of Tests}

Table 2 is a summary of the stove tests. It contains the test identification number (with the letter corresponding to the wood stove), the test date and duration, the average indoor-outdoor air temperature difference $(\Delta \mathrm{T})$ during the test, the mass of wood burned during the test, the percent moisture content (dry basis) of the wood burned, the number of times the stove was fueled, and the number of times the stove door was opened during the test. The duration of the test is the time from the start of the fire until it was burned out. The end time was determined by the static pressure measured in the stove flue. The mass of wood burned during the test includes the kindling, usually about $2.3 \mathrm{~kg}(5 \mathrm{lb})$. The number of stove door openings includes every time the door was opened to start the fire, load wood or tend the fire.

Table 2 Summary Table of Stove Tests

$\begin{array}{lccccccc}\text { Test ID } & \text { Date } & \begin{array}{c}\text { Duration } \\ \text { (h) }\end{array} & \Delta \mathrm{T}\left({ }^{\circ} \mathrm{C}\right) & \begin{array}{c}\text { Wood } \\ \text { burned }(\mathrm{kg})\end{array} & \begin{array}{c}\text { Moisture } \\ \text { content }(\%)\end{array} & \begin{array}{c}\text { Number of } \\ \text { fuelings }\end{array} & \begin{array}{c}\text { Number of } \\ \text { door openings }\end{array} \\ \text { A.1 } & 2 / 23 / 94 & 11.2 & 23.9 & 22.4 & 26 & 5 & 5 \\ \text { A.2 } & 2 / 25 / 94 & 14.8 & 17.7 & 16.5 & 28 & 5 & 6 \\ \text { A.3 } & 2 / 28 / 94 & 11.9 & 25.4 & 17.7 & 26 & 5 & 5 \\ \text { A.4 } & 3 / 02 / 94 & 9.3 & 22.1 & 16.7 & 28 & 6 & 6 \\ \text { B.2 } & 3 / 16 / 94 & 16.9 & 30.1 & 31.1 & 30 & 8 & 8 \\ \text { B.3 } & 3 / 17 / 94 & 13.8 & 27.3 & 25.7 & 25 & 8 & 8 \\ \text { B.4 } & 3 / 22 / 94 & 11.8 & 22.4 & 22.3 & 24 & 6 & 7 \\ & & & & & & & \\ \text { C.1 } & 3 / 29 / 94 & 12.2 & 22.7 & 18.4 & 23 & 8 & 9 \\ \text { C.2 } & 3 / 30 / 94 & 12.6 & 21.2 & 16.6 & 21 & 8 & 10 \\ \text { C.3 } & 3 / 31 / 94 & 10.9 & 21.6 & 14.8 & 16 & 6 & 9 \\ & & & & & & & \\ \text { D.1 } & 4 / 07 / 94 & 14.4 & 27.6 & 20.6 & 17 & 7 & 8 \\ \text { D.2 } & 4 / 08 / 94 & 11.7 & 27.0 & 17.9 & 16 & 9 & 7 \\ \text { D.3 } & 4 / 21 / 94 & 12.5 & 23.7 & 17.7 & 17 & 6 & 7\end{array}$

Blank Test, No Stove Operating
E.1
$4 / 22 / 94$
12.3

13.2 
The stove tests were performed between the end of February, 1994 and the third week in April. Three acceptable tests were performed on each stove, except for stove A, which was tested four times. As the test dates moved into the spring season, the tests on stoves B, C and D were conducted overnight. Testing at night increased the indoor-outdoor temperature difference and eliminated the solar load on the test house, thereby preventing overheating of the test house. A small number of tests were aborted or otherwise not included in the list due to instrumentation problems. Test E.1 was performed without a fire in the stove, but with all of the test instruments operating. The stove tests generally lasted 10 to $12 \mathrm{~h}$, and the average indoor-outdoor temperature difference was generally 20 to $30^{\circ} \mathrm{C}\left(36\right.$ to $\left.54^{\circ} \mathrm{F}\right)$. The number of door openings for stoves A and B were generally the same as the number of fuelings because the wood burned evenly and there was no need to tend the fire. However, the wood in stoves C and D did not burn completely without being rearranged periodically, and therefore the number of door openings is larger than the number of fuelings for these two stoves.

\section{Test Results}

Table 3 is a summary of the results of a typical stove test, specifically test C.1. Test result summary tables for all the tests are presented in Appendix C. The summary tables contain hourly average values for the following parameters: indoor and outdoor temperatures, wind speed, the difference between indoor and outdoor carbon monoxide concentrations, indoor and outdoor carbon dioxide concentrations, particle count concentrations for the six particle size ranges measured, flue and wall pressures, real-time total particulate-phase PAH concentrations and air change rates. The air change rates are two-hour averages. The fueling schedule is also given, containing the time and mass of each fuel loading. The start and stop times of the long and short PAH and PM10 samples are also contained in the table. The results of the PM10 measurements are presented in the table for the long and short samples of the indoor and outdoor air. These results include an estimate of the uncertainty in the particulate levels based on the uncertainties in the air sample volume and in the determination of the mass collected. The results of the PAH concentration measurements with the sorbent tubes are discussed in the next section.

Based on the objective of the study, the analysis of the test results concentrates on the determination of PAH emission rates as discussed in the next section. However, the test result summary tables contain a great deal of information. The increase in carbon monoxide concentrations in the test house during test C.1 is less than $1 \mathrm{ppm}$. In other tests, the indoor CO levels were 1 to $2 \mathrm{ppm}$ above outdoors. Indoor carbon dioxide concentrations were significantly higher than outdoors, but this was due primarily to the presence of people in the test house and not to the stove operation. The flue and wall pressures show the impact of the stove operation. During the fires the flue pressure is about $10 \mathrm{~Pa}$ below the pressure in the house, and the house pressure is about $1 \mathrm{~Pa}$ lower than outside. The total PAH concentrations from the real time monitor are variable during the tests, depending on whether the stove door was open during a given hour. The maximum concentrations also vary widely between tests from tens to thousands of $\mathrm{ng} / \mathrm{m}^{3}$. In test C. 1 , the first air change rate was determined for a two-hour period before the test started and is lower than the air change rates measured during the test. An increased air change rate during stove operation was observed in all tests due to the pressures induced by the stove. The increase in the air change rate varied among the tests, but generally ranged from 0.1 to $0.2 \mathrm{~h}^{-1}$. The measured PM10 concentrations in test C. 1 are higher indoors than outdoors, and this is true for most of the other tests as well. However, the difference between the indoor and outdoor concentrations is variable among the tests, and in some tests the concentrations are essentially the same. In most tests, the outdoor concentration is not significantly different from zero. 


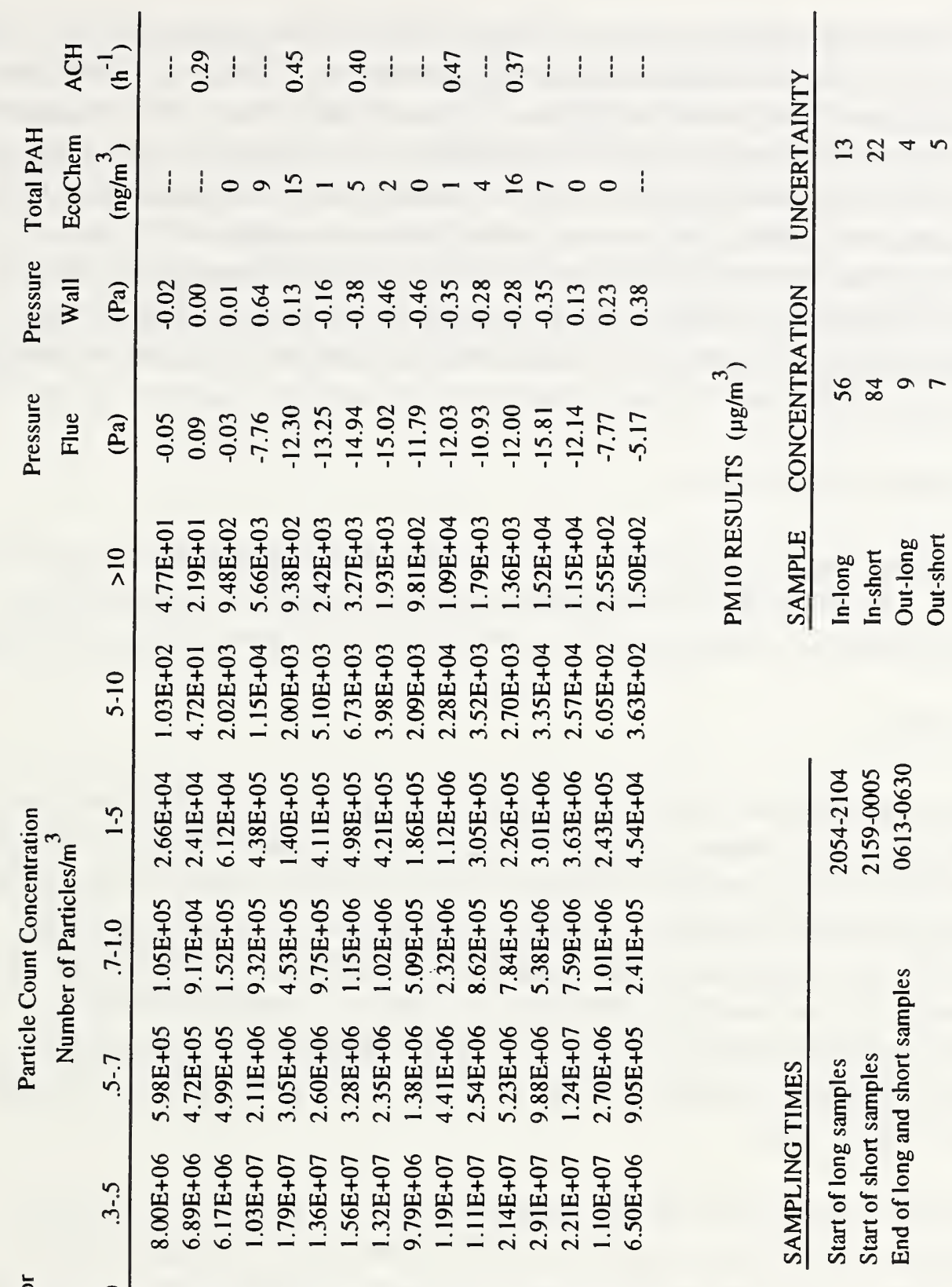





这

总

声 \&

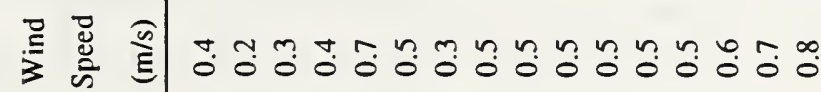

造

罚

כo 0 onnonoomo-manhrm

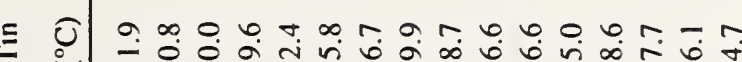

言席

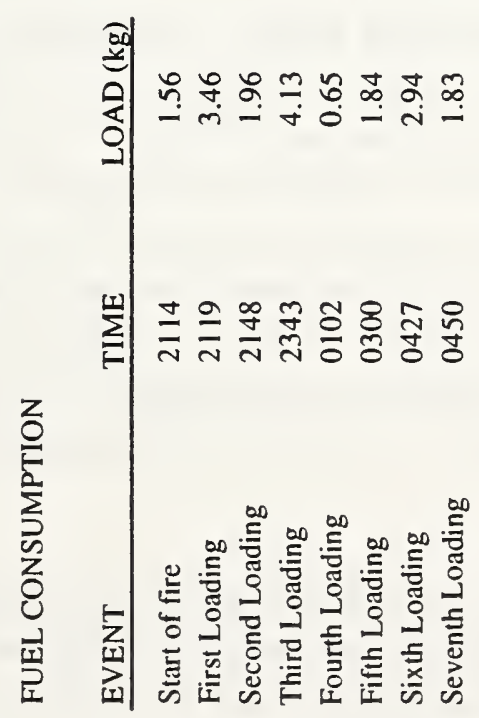


Figure 4 is a plot of the response of the real-time PAH monitor during test D.3. This plot shows the typical course of PAH concentrations during a stove test. The times of the start of the fire and the fuel loadings are identified in the figure. A peak in the indoor PAH concentration occurs when the stove door is opened to start or fuel the fire. The first peak was the largest because it includes the cumulative effect of three door openings over a 20 min period. The first door opening was to start the kindling, the second to fuel the stove with the first load of wood, and the third to fuel the stove with the second load of wood. The minimum concentration between peaks can not be seen in the figure, but it was generally between 0 and $10 \mathrm{ng} / \mathrm{m}^{3}$. Despite the care taken when opening the stove door, smoke still entered the interior volume of the test house, increasing the indoor PAH concentration in this test by a factor of about 100 .

\section{PAH Measurements with Sorbent Tubes}

This section presents and discusses the results of the PAH concentration measurements with the sorbent tubes. The concentrations themselves are presented first, followed by an analysis of these concentrations to determine indoor PAH emissions rates and source strengths.

\section{PAH Concentrations}

Average PAH concentrations were determined from the PAH mass collected on the sorbent tubes and the sample air volume. Table 4 contains the measured PAH concentrations from the indoor and outdoor long and short samples for all of the tests which were not aborted or eliminated due to instrumentation problems. These concentrations were determined by subtracting the mass of each compound on the blank tube for each test from the mass on the sample tube. The resultant mass was then divided by the sample volume to yield the concentration of each compound in units of $\mathrm{ng} / \mathrm{m}^{3}$. In tests A.4 and D.1, the sample blanks were not used due to analysis problems, and the average of all the other blanks was used as the blank values in the analysis of these tests.

Table 4 lists PAH compounds from benz[a]anthracene to indeno[1,2,3-cd]pyrene, because these compounds were of most interest to CPSC in their risk assessment and because the concentrations of the lower molecular weight compounds were relatively high in the no-stove test E.1. The table also contains the total PAH concentration for the eight compounds listed in the table. In this table $\mathrm{B}[\mathrm{a}] \mathrm{A}=$ benz $[\mathrm{a}]$ anthracene, $\mathrm{CHRYS}=$ chrysene, $\mathrm{PERY}=$ perylene, $\mathrm{B}[\mathrm{k}] \mathrm{F}=$ benzo[k]fluoranthene, $\mathrm{B}[\mathrm{a}] \mathrm{P}=$ benzo[a]pyrene, $\mathrm{DB}[\mathrm{ah}] \mathrm{A}=\operatorname{dibenz}[\mathrm{a}, \mathrm{h}]$ anthracene, $\mathrm{B}[\mathrm{ghi}] \mathrm{p}=$ benzo[ghi]perylene and INDEN = indeno[1,2,3-cd]pyrene. The entries denoted with the symbol * correspond to negative concentration values after the blank was subtracted, 0.0 entries correspond to values less than 0.05 after subtraction of the blank, and no entry corresponds to cases where the compound was not detected. Appendix D contains the measured PAH concentrations for all thirteen compounds that were analyzed. Table 4 shows that the outdoor $\mathrm{PAH}$ concentrations were higher than the corresponding indoor concentrations during some tests, presumably due to local wind patterns directing the flue gas towards the outdoor sampling location.

The precision of these concentrations was estimated based on an analysis of the duplicate samples, which revealed that a common within-duplicate precision was reasonable for the total PAH concentrations. Based on this assumption, the $95 \%$ confidence interval of the mean of duplicate total PAH concentrations is estimated to be $1.0 \mathrm{ng} / \mathrm{m}^{3}$. In some cases, this value of the 
uncertainty is larger than the mean value itself. When there is only one sample (no duplicate), the $95 \%$ confidence interval of the total PAH concentration is estimated to be $1.4 \mathrm{ng} / \mathrm{m}^{3}$. This estimate is based on the assumption that the variability of the duplicate pairs also applies to the measured values in which there was no duplicate. The analysis of the duplicate $\mathrm{B}[\mathrm{a}] \mathrm{P}$ concentrations revealed that it was not reasonable to assume a common within-duplicate precision. However, the relative standard deviation was fairly common across pairs. Therefore, the $95 \%$ confidence interval for the mean of duplicate $\mathrm{B}$ [a]P concentrations is estimated to be $20 \%$ of the mean concentration. In cases in which there is only one sample (no duplicate), the $95 \%$ confidence interval of the B [a]P concentration is estimated to be $29 \%$ of the concentration. 
Table 4 Summary of PAH Concentrations from Sorbent Tubes


$\begin{array}{llllllllll}\text { Test Sample } & \left(\mathrm{ng} / \mathrm{m}^{3}\right) & \left(\mathrm{ng} / \mathrm{m}^{3}\right) & \left(\mathrm{ng} / \mathrm{m}^{3}\right) & \left(\mathrm{ng} / \mathrm{m}^{3}\right) & \left(\mathrm{ng} / \mathrm{m}^{3}\right) & \left(\mathrm{ng} / \mathrm{m}^{3}\right) & \left(\mathrm{ng} / \mathrm{m}^{3}\right) & \left(\mathrm{ng} / \mathrm{m}^{3}\right) & \left(\mathrm{ng} / \mathrm{m}^{3}\right)\end{array}$

$\begin{array}{llccccccccc}\text { A.1 } & \text { In-Long } & * & * & 0.7 & 0.9 & 0.7 & & 2.4 & & 4.7 \\ & \text { In-Long } & * & 0.4 & 0.5 & 0.3 & 0.5 & 0.1 & 0.8 & 0.5 & 3.1 \\ & \text { In-Short } & * & 1.4 & 1.0 & 0.3 & 0.5 & * & 0.9 & 1.1 & 5.2 \\ & \text { In-Short } & 0.0 & 0.3 & 1.0 & 0.3 & 0.4 & * & 1.5 & & 3.5 \\ & \text { Out-Long } & * & * & 0.4 & 0.4 & 0.2 & & & & 1.0 \\ & & & & & & & & & & \\ \text { A.2 } & \text { In-Long } & 0.5 & 1.8 & 0.1 & 0.5 & 0.8 & 0.5 & 0.8 & 0.5 & 5.5 \\ & \text { In-Long } & 0.9 & 2.6 & 0.1 & 0.5 & 0.8 & 0.6 & 0.9 & 0.6 & 7.0 \\ & \text { In-Short } & * & 0.3 & * & 0.2 & 0.2 & 0.3 & 0.4 & 0.4 & 1.7 \\ & \text { In-Short } & 0.3 & 1.5 & 0.0 & 0.1 & 0.2 & 0.4 & 0.2 & 0.3 & 3.0 \\ & \text { Out-Long } & * & 0.3 & 0.1 & 0.3 & 0.5 & 0.1 & 0.4 & 0.6 & 2.3 \\ & \text { Out-Short } & 0.0 & 0.7 & 0.1 & 0.5 & 0.7 & 0.2 & 0.4 & 0.5 & 3.1\end{array}$

$\begin{array}{llccccccccc}\text { A.3 } & \text { In-Long } & * & 0.5 & 0.0 & 0.3 & 0.6 & 0.3 & 0.6 & 0.8 & 3.1 \\ & \text { In-Long } & * & 1.0 & 0.1 & 0.4 & 0.7 & 0.1 & 0.5 & 0.9 & 3.7 \\ & \text { In-Short } & * & 0.6 & 0.0 & 0.2 & 0.5 & 0.1 & 0.7 & 0.9 & 2.9 \\ & \text { In-Short } & * & 0.8 & 0.0 & 0.3 & 0.6 & 0.1 & 0.7 & 0.9 & 3.3 \\ & \text { Out-Long } & 0.5 & 0.4 & 0.0 & 0.2 & 0.2 & 0.0 & 0.1 & 0.2 & 1.6 \\ \text { Out-Short } & 0.0 & 0.4 & * & 0.1 & 0.1 & 0.0 & 0.3 & 0.2 & 1.1\end{array}$

\begin{tabular}{|c|c|c|c|c|c|c|c|c|c|}
\hline \multirow[t]{6}{*}{ A. 4} & In-Long & * & 0.1 & 0.1 & 0.1 & 0.2 & * & 0.1 & 0.3 \\
\hline & In-Long & $*$ & 0.1 & 0.0 & 0.1 & 0.2 & $*$ & 0.0 & 0.2 \\
\hline & In-Short & 0.1 & 0.0 & 0.0 & 0.1 & 0.2 & * & 0.0 & 0.2 \\
\hline & In-Short & 0.0 & 0.4 & 0.0 & 0.1 & 0.2 & $*$ & 0.0 & 0.3 \\
\hline & Out-Long & 0.0 & 0.1 & 0.1 & 0.2 & 0.2 & * & 0.5 & 0.3 \\
\hline & Out-Short & * & $*$ & 0.1 & 0.1 & 0.1 & * & $*$ & 0.2 \\
\hline
\end{tabular}

$\begin{array}{cllllllllll}\text { B.2 } & \text { In-Long } & 0.3 & 1.9 & 0.3 & 0.6 & 1.5 & 0.5 & 1.4 & 1.8 & 8.4 \\ & \text { In-Long } & 0.3 & 1.9 & 0.3 & 0.6 & 1.4 & 0.5 & 1.2 & 1.2 & 7.3 \\ & \text { In-Short } & 0.3 & 1.6 & 0.1 & 0.2 & 0.5 & 0.1 & 0.6 & 0.7 & 4.0 \\ \text { In-Short } & 0.1 & 1.4 & 0.1 & 0.2 & 0.3 & 0.2 & 0.5 & 0.4 & 3.1 \\ & \text { Out-Long } & 0.0 & 0.2 & 0.1 & 0.1 & 0.2 & 0.0 & 0.2 & 0.2 & 0.9 \\ & \text { Out-Short } & 0.0 & 0.2 & 0.1 & 0.1 & 0.1 & & & & 0.4 \\ & & & & & & & & & & \\ \text { B.3 } & & & & & & & & & \\ & \text { In-Long } & 0.4 & 1.5 & 0.0 & 0.1 & 0.2 & 0.1 & 0.2 & 0.5 & 3.0 \\ & \text { In-Long } & 0.3 & 1.4 & 0.1 & 0.1 & 0.2 & 0.1 & 0.4 & 0.4 & 3.0 \\ & \text { In-Short } & 0.2 & 1.2 & 0.0 & 0.1 & 0.1 & 0.1 & 0.3 & 0.2 & 2.3 \\ & \text { In-Short } & 0.2 & 0.8 & 0.0 & 0.1 & 0.1 & 0.1 & 0.5 & 0.2 & 2.0 \\ & \text { Out-Long } & 0.3 & 1.1 & 0.1 & 0.4 & 0.6 & 0.3 & 0.6 & 0.3 & 3.6 \\ & \text { Out-Short } & 0.4 & 0.7 & 0.1 & 0.3 & 0.4 & 0.1 & 0.4 & 0.3 & 2.7 \\ & & & & & & & & & & \\ & & & & & & & & & & \\ \text { B.4 In-Long } & * & 1.4 & 0.0 & 0.1 & 0.2 & 0.1 & 0.2 & 0.1 & 1.9 \\ & \text { In-Long } & * & 0.3 & 0.1 & 0.1 & 0.1 & 0.0 & 0.1 & 0.2 & 0.8 \\ & \text { In-Short } & * & 0.4 & 0.0 & 0.1 & 0.1 & 0.1 & 0.1 & & 0.9 \\ & \text { In-Short } & * & 0.1 & 0.0 & 0.1 & 0.1 & 0.1 & 0.1 & & 0.5 \\ \text { Out-Long } & * & 0.0 & 0.1 & 0.3 & 0.4 & 0.1 & 0.6 & 0.3 & 1.7 \\ \text { Out-Short } & * & 0.1 & 0.1 & 0.3 & 0.4 & 0.1 & 0.8 & 0.5 & 2.1\end{array}$




\begin{tabular}{|c|c|c|c|c|c|c|c|c|c|c|}
\hline Test & Sample & $\begin{array}{l}\mathrm{B}[\mathrm{a}] \mathrm{A} \\
\left(\mathrm{ng} / \mathrm{m}^{3}\right)\end{array}$ & $\begin{array}{l}\text { CHRYS } \\
\left(\mathrm{ng} / \mathrm{m}^{3}\right)\end{array}$ & $\begin{array}{l}\text { PERY } \\
\left(\mathrm{ng} / \mathrm{m}^{3}\right)\end{array}$ & $\begin{array}{c}\mathrm{B}[\mathrm{k}] \mathrm{F} \\
\left(\mathrm{ng} / \mathrm{m}^{3}\right)\end{array}$ & $\begin{array}{c}\mathrm{B}[\mathrm{a}] \mathrm{P} \\
\left(\mathrm{ng} / \mathrm{m}^{3}\right)\end{array}$ & $\begin{array}{c}\mathrm{DB}[\mathrm{ah}] \mathrm{A} \\
\left(\mathrm{ng} / \mathrm{m}^{3}\right)\end{array}$ & $\begin{array}{l}\mathrm{B}[\mathrm{ghi}] \mathrm{P} \\
\left(\mathrm{ng} / \mathrm{m}^{3}\right)\end{array}$ & $\begin{array}{l}\text { INDENO } \\
\left(\mathrm{ng} / \mathrm{m}^{3}\right)\end{array}$ & $\begin{array}{l}\text { Total } \\
\left(\mathrm{ng} / \mathrm{m}^{3}\right)\end{array}$ \\
\hline \multirow[t]{4}{*}{ C. 1} & In-Long & 0.5 & 0.7 & 0.0 & 0.1 & 0.2 & * & 0.3 & 0.7 & 2.4 \\
\hline & In-Long & 0.3 & 0.7 & 0.0 & 0.1 & 0.1 & * & 0.3 & 0.1 & 1.5 \\
\hline & In-Short & 0.4 & 1.4 & 0.2 & 0.1 & 0.1 & * & 0.1 & 0.2 & 2.5 \\
\hline & In-Short & 0.2 & 1.2 & 0.0 & 0.1 & 0.2 & & & 0.1 & 1.8 \\
\hline \multirow[t]{6}{*}{ C. 2} & In-Long & 0.1 & 0.9 & 0.1 & 0.1 & 0.2 & 0.7 & 0.3 & & 2.5 \\
\hline & In-Long & 0.2 & 1.4 & 0.1 & 0.1 & 0.2 & 0.8 & 0.5 & 0.2 & 3.6 \\
\hline & In-Short & 0.1 & 1.0 & 0.1 & 0.1 & 0.2 & 0.8 & 0.4 & 0.3 & 3.0 \\
\hline & In-Short & $*$ & 0.8 & 0.1 & 0.3 & 0.2 & 0.1 & 0.2 & & 1.6 \\
\hline & Out-Long & 0.1 & 1.7 & 0.3 & 0.7 & 1.3 & 0.4 & 1.3 & & 5.8 \\
\hline & Out-Short & 0.1 & 1.9 & 0.4 & 0.7 & 1.4 & 0.3 & 1.4 & 1.3 & 7.5 \\
\hline \multirow[t]{6}{*}{ C. 3} & In-Long & * & 1.0 & 0.1 & 0.1 & 0.1 & & & & 1.3 \\
\hline & In-Long & $*$ & 1.0 & 0.1 & 0.1 & 0.1 & 0.0 & 0.1 & & 1.4 \\
\hline & In-Short & $*$ & 0.2 & 0.2 & 0.1 & 0.1 & 0.1 & 0.2 & & 0.8 \\
\hline & In-Short & $*$ & 1.1 & 0.1 & 0.1 & 0.1 & 0.1 & 0.1 & & 1.6 \\
\hline & Out-Long & * & 0.2 & 0.2 & 0.2 & 0.1 & & 0.3 & 0.2 & 1.2 \\
\hline & Out-Short & $*$ & 0.0 & 0.1 & 0.1 & 0.2 & & & & 0.4 \\
\hline \multirow[t]{6}{*}{ D.1 } & In-Long & 0.1 & 2.1 & 0.1 & 0.1 & 0.3 & 0.0 & 0.1 & 0.5 & 3.3 \\
\hline & In-Long & 0.0 & 3.7 & 0.1 & 0.1 & 0.3 & * & 0.2 & 0.3 & 4.9 \\
\hline & In-Short & * & 1.6 & 0.0 & 0.1 & 0.2 & * & 0.0 & 0.3 & 2.2 \\
\hline & In-Short & 0.1 & 2.0 & 0.0 & 0.1 & 0.2 & * & 0.0 & 0.7 & 3.1 \\
\hline & Out-Long & $*$ & $*$ & 0.0 & 0.1 & 0.1 & * & 0.0 & 0.2 & 0.4 \\
\hline & Out-Short & 0.1 & * & 0.0 & 0.1 & 0.1 & & & & 0.3 \\
\hline \multirow[t]{6}{*}{ D. 2} & In-Long & 1.1 & 2.3 & 0.1 & 0.1 & 0.2 & 1.0 & 0.4 & 0.4 & 5.6 \\
\hline & In-Long & 1.0 & 3.0 & 0.1 & 0.1 & 0.2 & 0.9 & 0.3 & 0.2 & 5.9 \\
\hline & In-Short & 0.9 & 2.7 & 0.1 & 0.1 & 0.2 & 1.0 & 0.2 & & 5.1 \\
\hline & In-Short & 0.9 & 2.4 & 0.1 & 0.1 & 0.1 & 0.8 & 0.3 & 0.5 & 5.1 \\
\hline & Out-Long & * & 0.6 & 0.1 & 0.2 & 0.2 & 0.7 & 0.4 & & 2.1 \\
\hline & Out-Short & 0.1 & 0.4 & 0.1 & 0.1 & 0.1 & 0.7 & 0.2 & & 1.8 \\
\hline \multirow[t]{6}{*}{ D. 3} & In-Long & 1.1 & 3.7 & * & 0.2 & 0.4 & 0.1 & 0.4 & 0.6 & 6.4 \\
\hline & In-Long & 1.4 & 3.5 & * & 0.2 & 0.3 & 0.1 & 0.3 & 0.5 & 6.4 \\
\hline & In-Short & 0.7 & 2.8 & * & 0.1 & 0.1 & 0.1 & 0.3 & 0.3 & 4.4 \\
\hline & In-Short & 1.0 & 3.0 & * & 0.1 & 0.1 & 0.1 & 0.3 & 0.2 & 4.8 \\
\hline & Out-Long & 0.3 & 0.2 & * & 0.1 & 0.1 & & & & 0.6 \\
\hline & Out-Short & 1.1 & 0.4 & * & 0.1 & 0.1 & & & & 1.6 \\
\hline \multirow[t]{5}{*}{ E.1 } & In-Long & 0.4 & 0.8 & 0.0 & 0.0 & 0.0 & & & & 1.3 \\
\hline & In-Long & 0.1 & 0.9 & 0.0 & & & & & & 1.0 \\
\hline & In-Short & 0.1 & 0.7 & 0.1 & 0.0 & 0.0 & & & & 1.0 \\
\hline & Out-Long & 0.3 & 0.1 & 0.0 & 0.0 & 0.0 & 0.0 & 0.2 & 0.3 & 1.0 \\
\hline & Out-Short & 0.4 & 0.1 & 0.1 & 0.0 & & & & & 0.6 \\
\hline
\end{tabular}




\section{PAH Emission Rates}

In order to generalize the measured PAH concentrations in the test house to situations in buildings with different air change rates and interior volumes and with different rates of wood consumption, it is necessary to compute PAH emission rates and source strengths from the test results. In the analysis that follows, the term emission rate refers to the mass of PAH emitted per unit time, and the term source strength refers to the mass of PAH emitted per mass of wood burned. These emission rates, in units of $\mathrm{ng} / \mathrm{s}$, and source strengths, in units of $\mathrm{ng} / \mathrm{kg}$ of wood burned, are obtained by performing a single-zone mass balance analysis on the test house. The single-zone mass balance equation, in its instantaneous form, is given as:

$$
\mathrm{V} \frac{\mathrm{dC}_{\text {in }}}{\mathrm{dt}}=\mathrm{E}+\mathrm{PQC}_{\text {out }}-\mathrm{QC}_{\text {in }}-\mathrm{KVC}_{\text {in }}
$$

where

$$
\begin{aligned}
& V=\text { test house volume }\left(\mathrm{m}^{3}\right) \\
& C_{\text {in }}=\text { indoor concentration of total or individual PAH }\left(\mathrm{ng} / \mathrm{m}^{3}\right) \\
& \mathrm{E}=\text { total or individual PAH emission rate }(\mathrm{ng} / \mathrm{s}) \\
& \mathrm{P}=\text { penetration factor for outdoor total or individual PAH } \\
& \mathrm{Q}=\text { airflow rate of outdoor air into the test house }\left(\mathrm{m}^{3} / \mathrm{s}\right) \\
& C_{\text {out }}=\text { outdoor concentration of total or individual PAH }\left(\mathrm{ng} / \mathrm{m}^{3}\right) \\
& k=\text { indoor decay rate of total or individual PAH }\left(\mathrm{s}^{-1}\right)
\end{aligned}
$$

The objective of these tests was to determine PAH emission rates and source strengths based on the concentrations measured with the long and short sorbent tubes. However, since these concentrations are averages over a period of several hours, the instantaneous form of the mass balance equation cannot be used. Instead, the mass balance equation is integrated with respect to time to yield the following equation:

$$
V\left(C_{\text {final }}-C_{\text {initial }}\right)=\overline{\mathrm{E} T}+\mathrm{P} \overline{\mathrm{Q}} \overline{\mathrm{C}}_{\text {out }} \mathrm{T}-\overline{\mathrm{Q}} \overline{\mathrm{C}}_{\text {in }} \mathrm{T}-\mathrm{kV} \overline{\mathrm{C}}_{\text {in }} \mathrm{T}
$$

where

$$
\begin{aligned}
& \mathrm{C}_{\text {final }}=\text { the indoor total or individual PAH concentration at the end of the sampling } \\
& \text { period }\left(\mathrm{ng} / \mathrm{m}^{3}\right) \\
& \mathrm{C}_{\text {initial }}=\text { the indoor total or individual PAH concentration at the beginning of the sampling } \\
& \text { period }\left(\mathrm{ng} / \mathrm{m}^{3}\right) \\
& \mathrm{T}=\text { the duration of the sampling period(s) }
\end{aligned}
$$


The quantities with an overbar (e.g., $\overline{\mathrm{E}}$ ) are the average values of the respective quantity over the sampling period. Equation 2 is based on an assumption that $\mathrm{P}$ and $\mathrm{k}$ are constant throughout the sampling period. Also, the indoor PAH concentration is assumed to be uniform within the test house. The average values of the products $\mathrm{QC}_{\text {out }}$ and $\mathrm{QC}_{\mathrm{in}}$ are approximated by the product of their averages. Equation 2 can be solved for the average emission rate during the sampling period as follows,

$$
\overline{\mathrm{E}}=\mathrm{V} \frac{\Delta \mathrm{C}}{\mathrm{T}}+\overline{\mathrm{Q}} \overline{\mathrm{C}}_{\mathrm{in}}+\mathrm{kV} \overline{\mathrm{C}}_{\text {in }}-\mathrm{PQ} \overline{\mathrm{C}}_{\text {out }}
$$

where $\Delta C$ equals $\mathrm{C}_{\text {final }}$ minus $\mathrm{C}_{\text {initial. }}$. The average emission rate can then be divided by the average rate of wood consumption for the corresponding time period to yield the average PAH (total or individual) source strength over the same time period per kilogram of wood burned.

Steady-state mass balance approaches have been used previously to determine emission rates and source strengths (Knight and Humphreys 1985, Sheldon et al. 1993b, Traynor et al. 1987). In these efforts, the PAH concentration was assumed to be at steady-state, and the term containing $\Delta \mathrm{C}$ in Equation 3 was neglected. Depending on the stove operation at the beginning and end of the sampling period, it may be inappropriate to neglect this term.

Equation 3 was used to determine the emission rates and source strengths of $\mathrm{B}[\mathrm{a}] \mathrm{P}$ and total PAH, where total PAH is the sum of the concentrations of the eight individual compounds in Table 4. Several key parameters are required to use Equation 3 to determine these emission rates: $\Delta \mathrm{C}$ for $\mathrm{B}[\mathrm{a}] \mathrm{P}$ and total $\mathrm{PAHs}$, the indoor decay rate $\mathrm{k}$ for $\mathrm{B}[\mathrm{a}] \mathrm{P}$ and total $\mathrm{PAHs}$, the penetration factor $\mathrm{P}$ for $\mathrm{B}[\mathrm{a}] \mathrm{P}$ and total $\mathrm{PAHs}$, and the average rate of wood consumption during the long and short sampling periods. The value of $\Delta \mathrm{C}$ can not be determined directly for $\mathrm{B}[\mathrm{a}] \mathrm{P}$ and total PAHs, because only average values of these concentrations were determined with the sorbent tubes. Instead, an approximate value of $\triangle \mathrm{C}$ was obtained based on the output of the real-time PAH monitor used in these tests. To estimate the value of $\Delta \mathrm{C}$ for the total PAHs over a sampling period, the ratio of the total PAH concentration determined with the sorbent tube to the average concentration from the real-time PAH monitor over the period was determined. This ratio $\beta_{\text {total }}$ is defined as

$$
\beta_{\text {total }}=\frac{\text { Total PAH concentration from sorbent tube }}{\text { Average PAH concentration from real-time monitor }} .
$$

The concentration from the real-time PAH monitor at the end of the sampling period was then subtracted from the concentration from the monitor at the beginning of the sample period. This difference was then multiplied by $\beta_{\text {total }}$ to estimate $\Delta \mathrm{C}$ for the total PAH concentration.

To estimate the value of $\Delta \mathrm{C}$ for $\mathrm{B}[\mathrm{a}] \mathrm{P}$ over a sampling period, the ratio of the $\mathrm{B}[\mathrm{a}] \mathrm{P}$ concentration determined with the sorbent tube to the average concentration from the real-time $\mathrm{PAH}$ monitor over the period was determined. This ratio $\beta_{\mathrm{B}[\mathrm{a}] \mathrm{P}}$ is defined as

$$
\beta_{\mathrm{B}[\mathrm{a}] \mathrm{P}}=\frac{\mathrm{B}[\mathrm{a}] \mathrm{P} \text { concentration from sorbent tube }}{\text { Average PAH concentration from real-time monitor }} .
$$


The concentration from the real-time PAH monitor at the end of the sampling period was then subtracted from the concentration from the monitor at the beginning of the sample period. This difference was then multiplied by the ratio $\beta_{\mathrm{B}[\mathrm{a}] \mathrm{P}}$ to estimate $\Delta \mathrm{C}$ for $\mathrm{B}[\mathrm{a}] \mathrm{P}$.

The indoor decay rate $\mathrm{k}$ accounts for the loss of indoor PAHs through mechanisms other than dilution with outdoor air, primarily deposition on interior surfaces. The value of $k$ for the test house was obtained by calculating a PAH decay rate based on the concentration determined with the real-time PAH monitor and comparing this value to the decay of the sulfur hexafluoride $\left(\mathrm{SF}_{6}\right)$. The PAH decay rate was determined on several occasions, when the indoor concentration had become elevated after the stove door was opened. The $\mathrm{SF}_{6}$ decay rate for the same time period was then subtracted from the real-time PAH decay rate. Twelve such decay rate comparisons were made, and the results are presented in Table 5 in units of $\mathrm{h}^{-1}$. This table includes two results from test A.5, however, PAH emission rates are not reported for this test due to data collection problems. The average value of $\mathrm{k}$ for these twelve decays is $3.47 \times 10^{-4} \mathrm{~s}^{-1}$ $\left(1.25 \mathrm{~h}^{-1}\right)$. This value was used for both the total PAH and $\mathrm{B}[\mathrm{a}] \mathrm{P}$ emission rate and source strength calculations. This compares to values of $\mathrm{k}$ of $0.14 \times 10^{-4} \mathrm{~s}^{-1}\left(0.05 \mathrm{~h}^{-1}\right)$ used by Knight and Humphreys (1985) and $0.22 \times 10^{-4} \mathrm{~s}^{-1}\left(0.08 \mathrm{~h}^{-1}\right)$ used by Traynor et al. (1987). The value used by Knight and Humphreys is presented with no explanation, however the value used by Traynor was determined in a test house by comparing measured particle decay rates with measured carbon monoxide decay rates. However, the particle decay rates were based only on particles with diameters of $0.6 \mu \mathrm{m}$ or less and there were no mixing fans operating in the house at the time. The values presented in Table 5 are larger due to the existence of particles with diameters larger than $0.6 \mu \mathrm{m}$ and the operation of a ducted mixing fan during the tests.

Table 5 Summary of PAH Decay Tests

\section{Decay Test \# Stove Test \#}

1

2

3

4

5

6

7

8

9

10

11

12
A. 1

A. 2

A. 2

A. 4

A. 5

A. 5

B. 1

B. 3

C. 3

D. 1

D. 1

D. 1
Decay Rate $\left(\mathrm{h}^{-1}\right)$

$\mathrm{PAH}$

1.30

1.79

1.84

1.07

1.55

1.48

2.14

1.97

1.15

2.22

1.68

1.69
$\mathrm{SF}_{6}$

0.35

0.42

0.22

0.27

0.64

0.47

0.58

0.39

0.34

0.50

0.16

0.54
PAH Decay Rate

$\mathrm{k}\left(\mathrm{h}^{-1}\right)$

0.95

1.37

1.62

0.80

0.91

1.01

1.56

1.58

0.81

1.72

1.52

1.15

Average

1.25

Standard Deviation $\quad 0.35$ 
A penetration factor $\mathrm{P}$ of 0.5 was used in these analyses for both $\mathrm{B}[\mathrm{a}] \mathrm{P}$ and total PAHs. This is the same value used by Knight and Humphreys (1985). It is also close to the average value of $\mathrm{P}(0.48)$ determined by Traynor et al. (1987) for several individual PAH compounds. Because of the relatively low outdoor PAH concentrations in most tests, the value of $\mathrm{P}$ is not critical to the mass balance analysis.

The average wood consumption rates for the long and short sampling periods were determined based on the time and mass of the individual fuel loadings. The mass of each fuel loading is designated as $M_{i}$. The average wood consumption rate for the long sample $\dot{M}_{L}$ was determined by dividing the total mass of the wood consumed by the length of time $T_{L}$ from the beginning of the test to the time that the fire burned out. If there were $\mathrm{N}$ fuel loadings during the test, then $\dot{\mathrm{M}}_{\mathrm{L}}$ is given by the equation:

$$
\dot{\mathrm{M}}_{\mathrm{L}}=\frac{1}{\mathrm{~T}_{\mathrm{L}}} \sum_{1}^{\mathrm{N}} \mathrm{M}_{\mathrm{i}} .
$$

The average wood consumption rate for the short sampling period is based on the mass of wood consumed starting with the load before the start of the short sampling period. The fuel loaded just prior to the start of the short sampling period is designated as $M_{s} . T_{s}$ is the length of time between this fuel loading and the end of the fire. The average wood consumption rate during the short sampling period $\dot{\mathrm{M}}_{\mathrm{s}}$ is given by the equation:

$$
\dot{\mathrm{M}}_{\mathrm{S}}=\frac{1}{\mathrm{~T}_{\mathrm{s}}} \sum_{\mathrm{S}}^{\mathrm{N}} \mathrm{M}_{\mathrm{i}}
$$

The values of $\mathrm{C}_{\text {in }}$ and $\mathrm{C}_{\text {out }}$ used in Equation 3 were obtained from Table 4. The value of $\mathrm{Q}$ was based on the average air change rate during the appropriate sample period (long or short) multiplied by the volume of the test house.

Based on the uncertainty in the estimate of the storage term in Equation 3, V $\Delta \mathrm{C} / \mathrm{T}$, only those tests for which this term is less than $10 \%$ of the calculated value of $E$ are reported.

Figures 5 through 8 show the calculated emission rates in units of $\mathrm{ng} / \mathrm{s}$ and source strengths in units of $\mathrm{ng} / \mathrm{kg}$ of wood burned for $\mathrm{B}[\mathrm{a}] \mathrm{P}$ and total PAHs. These graphs show the results for all the tests that were acceptable in terms of the errors associated with the storage term and other considerations. The duplicate sample results for both the long and short samples are displayed in the graphs. Figure 5 shows the emission rate of total PAHs in units of ng/s, and Figure 6 shows the total PAH source strength in units of $\mathrm{ng} / \mathrm{kg}$ of wood. The precision of these emission rates and source strengths was estimated based on an analysis of the duplicate samples. This analysis revealed that a common within-duplicate precision was reasonable for the total PAH emission rates and source strengths. Based on this assumption, the $95 \%$ confidence intervals of the mean of duplicate total PAH emission rate and source strength are estimated to be $0.04 \mathrm{ng} / \mathrm{s}$ and $95 \mathrm{ng} / \mathrm{kg}$ of wood burned, respectively. When there is only one sample (no duplicate), the $95 \%$ confidence intervals of the total PAH emission rate and source strength are estimated to be $0.06 \mathrm{ng} / \mathrm{s}$ and $138 \mathrm{ng} / \mathrm{kg}$. As was the case for the concentrations, these single-sample estimates of the confidence intervals are based on the assumption that the variability of the duplicate pairs also applies to the measured values in which there was no duplicate. 
Figure 7 shows the emission rate of $\mathrm{B}[\mathrm{a}] \mathrm{P}$ in units of $\mathrm{ng} / \mathrm{s}$, and Figure 8 shows the $\mathrm{B}[\mathrm{a}] \mathrm{P}$ source strength in units of $\mathrm{ng} / \mathrm{kg}$ of wood. The analysis of the duplicate $\mathrm{B}[\mathrm{a}] \mathrm{P}$ emission rates and source strengths revealed that it was not reasonable to assume a common within-duplicate precision. However, the relative standard deviation was consistent across pairs. The $95 \%$ confidence interval for the mean of duplicate $\mathrm{B}[\mathrm{a}] \mathrm{P}$ emission rates and source strengths are estimated to be $28 \%$ of the mean value for emission rates as a function of time and for source strengths as a function of wood burned. In cases in which there is only one sample (no duplicate), the $95 \%$ confidence intervals of the B[a]P emission rates and source strengths are estimated to be $39 \%$ of the mean value.

An analysis of variance was performed to examine the variation in emission rate and source strength as a function of stove type, long versus short samples, numbers of fuelings and number of stove door openings. The results of this analysis revealed that while there was a statistically significant difference between the results of the individual tests, there was no statistically significant effect of any of the parameters examined (stove type, sample length, number of fuelings and number of stove door openings) on the measured emission rates and source strengths. The only exception is that there is a statistically significant difference among the stoves $(\mathrm{A}, \mathrm{B}, \mathrm{C}$ and $\mathrm{D})$ in the $\mathrm{B}[\mathrm{a}] \mathrm{P}$ emission rates.

Given the lack of any significant effect of the parameters mentioned above, the mean emission rate and source strength was calculated for each test and the results are presented in Tables 6 and 7. These tables include only those tests for which there is more than one value from which to calculate the mean. Table 6 contains the mean emission rate for total PAHs in units of $\mathrm{ng} / \mathrm{s}$ and source strength in units of $\mathrm{ng} / \mathrm{kg}$ of wood burned. Table 7 contains the mean emission rates and source strengths for $\mathrm{B}[\mathrm{a}] \mathrm{P}$. The means are presented with the uncertainty expressed as the $95 \%$ confidence intervals, which in turn depend on the number of values used to determine the mean. The values of the uncertainty in the emission rate and source strength of total PAHs in Table 6 are only a function of the number of values used to determine the mean and are large relative to the lower emission rates. For example, in test B.4 the uncertainty is essentially equal to the mean. The uncertainty for the emission rates and source strengths of $\mathrm{B}[\mathrm{a}] \mathrm{P}$ in Table 7 is a percentage of the mean value, and again depends on the number of values used to determine the mean. These uncertainties are between $25 \%$ and $35 \%$ of the mean value.

Referring to Table 6, the emission rate of total PAHs ranges from 0.03 to $0.24 \mathrm{ng} / \mathrm{s}$. The mean value is $0.13 \mathrm{ng} / \mathrm{s}$, and the median value is $0.12 \mathrm{ng} / \mathrm{s}$. The source strength relative to the wood burning rate ranges from 67 to $711 \mathrm{ng} / \mathrm{kg}$ of wood burned. The mean value is $360 \mathrm{ng} / \mathrm{kg}$, and the median is $332 \mathrm{ng} / \mathrm{kg}$. The emission rates for $\mathrm{B}$ [a]P in Table 7 range from 0.003 to $0.028 \mathrm{ng} / \mathrm{s}$, with a mean value of $0.012 \mathrm{ng} / \mathrm{s}$ and a median of $0.009 \mathrm{ng} / \mathrm{s}$. The B[a]P source strengths relative to the wood burning rate range from 7 to $90 \mathrm{ng} / \mathrm{kg}$. The mean value is $32 \mathrm{ng} / \mathrm{kg}$, and the median is $22 \mathrm{ng} / \mathrm{kg}$. For comparison, a paper by Traynor et al. (1987) reported $\mathrm{B}[\mathrm{a}] \mathrm{P}$ emission rates for seven tests of airtight wood stoves. The distribution of these emission rate values is skewed by one high value, so the mean value is not an appropriate summary statistic. The emission rates of $\mathrm{B}[\mathrm{a}] \mathrm{P}$ in this earlier study range from 0.006 to $0.211 \mathrm{ng} / \mathrm{s}$, and the median is $0.011 \mathrm{ng} / \mathrm{s}$. Accounting for wood burning rates, the source strengths in the Traynor study range from 8 to $174 \mathrm{ng} / \mathrm{kg}$ with a median value of $22 \mathrm{ng} / \mathrm{kg}$. The $\mathrm{B}$ [a]P emission rates and source strengths reported in the NIST study are similar to the values reported in this previous study. 
Table 6 Mean Emission Rates and Source Strengths of Total PAHs

Stove Test Emission Rate Uncertainty Source Strength Uncertainty $(\mathrm{ng} / \mathrm{s}) \quad(\mathrm{ng} / \mathrm{s}) \quad(\mathrm{ng} / \mathrm{kg}$ wood $) \quad(\mathrm{ng} / \mathrm{kg}$ wood $)$

$\begin{array}{lllll}\text { A.1 } & 0.16 & 0.03 & 332 & 69 \\ \text { A.2 } & 0.22 & 0.04 & 711 & 97 \\ \text { A.3 } & 0.12 & 0.03 & 357 & 69 \\ \text { B.2 } & 0.12 & 0.04 & 283 & 97 \\ \text { B.3 } & 0.09 & 0.03 & 192 & 69 \\ \text { B.4 } & 0.03 & 0.03 & 67 & 69 \\ \text { C.2 } & 0.09 & 0.04 & 249 & 97 \\ \text { C.3 } & 0.05 & 0.03 & 144 & 69 \\ \text { D.1 } & 0.14 & 0.03 & 374 & 69 \\ \text { D.2 } & 0.22 & 0.03 & 639 & 69 \\ \text { D.3 } & 0.24 & 0.04 & 615 & 97\end{array}$

Table 7 Mean Emission Rates and Source Strengths of B[a]P

Stove Test Emission Rate Uncertainty Source Strength Uncertainty $(\mathrm{ng} / \mathrm{s}) \quad(\mathrm{ng} / \mathrm{s}) \quad(\mathrm{ng} / \mathrm{kg}$ wood $) \quad(\mathrm{ng} / \mathrm{kg}$ wood $)$

$\begin{array}{llllr}\text { A.1 } & 0.020 & 0.006 & 41 & 10 \\ \text { A.2 } & 0.028 & 0.012 & 90 & 32 \\ \text { A.3 } & 0.023 & 0.007 & 66 & 17 \\ \text { A.4 } & 0.008 & 0.002 & 16 & 6 \\ \text { B.2 } & 0.013 & 0.006 & 31 & 11 \\ \text { B.3 } & 0.006 & 0.003 & 11 & 3 \\ \text { B.4 } & 0.003 & 0.001 & 7 & 2 \\ \text { C.3 } & 0.004 & 0.001 & 11 & 3 \\ \text { D.1 } & 0.010 & 0.003 & 27 & 7 \\ \text { D.2 } & 0.006 & 0.002 & 16 & 4 \\ \text { D.3 } & 0.013 & 0.006 & 33 & 12\end{array}$




\section{Carbon Monoxide Emission Rates}

Emission rates were also calculated for carbon monoxide using Equation 3. In these calculations, the penetration factor for $\mathrm{CO}$ was assumed to equal 1.0 and the decay factor $\mathrm{k}$ was assumed to equal 0 . Table 8 presents the emission rates and source strengths for those tests for which they could be determined in units of $\mu \mathrm{g} / \mathrm{s}$ and in $\mathrm{mg} / \mathrm{kg}$ of wood burned, along with the uncertainties in their values. The uncertainties are generally about 20 to $35 \%$ of the calculated value, except for very low emission rates and sources strengths (Tests C.1 and C.3) in which the uncertainty is similar in magnitude to the emission rates and source strengths themselves. The mean source strengths and emission rates in Table 8 are $12 \mu \mathrm{g} / \mathrm{s}$ and $36 \mathrm{mg} / \mathrm{kg}$ of wood burned. Traynor et al. (1987) reports $\mathrm{CO}$ emission rates for seven airtight wood stoves that range from 3 to $46 \mu \mathrm{g} / \mathrm{s}$, with a mean value of $23 \mu \mathrm{g} / \mathrm{s}$. Accounting for wood burning rates, the source strengths in the Traynor study range from 5 to $90 \mathrm{mg} / \mathrm{kg}$ with a mean value of $38 \mathrm{mg} / \mathrm{kg}$. The CO source strengths, based on wood burning rates, are very similar between the NIST and the Traynor studies.

Table 8 Mean Emission Rates and Source Strengths of Carbon Monoxide

$\begin{array}{ccccc}\text { Stove Test } & \begin{array}{c}\text { Emission Rate } \\ (\mu \mathrm{g} / \mathrm{s})\end{array} & \begin{array}{c}\text { Uncertainty } \\ (\mu \mathrm{g} / \mathrm{s})\end{array} & \begin{array}{c}\text { Source Strength } \\ (\mathrm{mg} / \mathrm{kg} \text { wood })\end{array} & \begin{array}{c}\text { Uncertainty } \\ (\mathrm{mg} / \mathrm{kg} \text { wood })\end{array} \\ \text { A.2 } & 18 & 4 & 62 & 16 \\ \text { A.3 } & 26 & 4 & 86 & 17 \\ \text { A.4 } & 8 & 2 & 19 & 6 \\ & & & & \\ \text { B.2 } & 10 & 3 & 22 & 8 \\ \text { B.3 } & 18 & 6 & 40 & 15 \\ \text { C.1 } & 3 & 4 & 9 & 12 \\ \text { C.3 } & 4 & 5 & 12 & 15 \\ & & & & \\ \text { D.1 } & 13 & 5 & 38 & 16 \\ \text { D.2 } & 11 & 6 & 34 & 19\end{array}$




\section{SUMMARY AND DISCUSSION}

In order to support a cancer risk assessment being performed by CPSC on wood stoves meeting the EPA Phase II emission requirements, indoor PAH emission rates were measured for four stoves. During the tests, the stoves were operated in a manner consistent with typical residential use and in accordance with the manufacturers' instructions. Emission rates and source strengths were determined for B[a]P and total PAHs, where this total included 8 compounds with retention times between that of benz[a]anthracene and indeno[1,2,3-cd]pyrene under the conditions of chromatography described previously. Based on three tests on each of the four stoves, the average $\mathrm{B}[\mathrm{a}] \mathrm{P}$ emission rate is $0.012 \mathrm{ng} / \mathrm{s}$ and the average total PAH emission rate is $0.13 \mathrm{ng} / \mathrm{s}$. Normalizing for the rate of wood consumption during each test, the average $\mathrm{B}$ [a]P source strength is $32 \mathrm{ng} / \mathrm{kg}$ of wood burned and the average PAH source strength is $360 \mathrm{ng} / \mathrm{kg}$ of wood. No statistically significant relationship was found between the measured emission rates or source strengths and the stoves (A, B, C and D), length of sampling period, number of fuelings or number of stove door openings. It may be that the variation in the emission rate and source strength among the tests is due to the manner in which the stove was operated, specifically the care in opening the stove door and vents. In these tests, great care was taken when opening the door to minimize the release of wood smoke to the indoors, and in many cases the release was minimal. In other cases, despite the care taken, a significant quantity of wood smoke was released to the indoors. In actual residential buildings, the indoor PAH emissions from a stove will presumably be more variable due to differences in use patterns in among residences and variations in the care taken by the occupants in opening the stove door. Another factor affecting indoor PAH emissions in real homes is the pressure in the space containing the wood stove and how it is affected by building height, the distribution of leaks in the building envelope, weather conditions and the condition and operation of other appliances (e.g., exhaust fans and forced-air systems). 


\section{REFERENCES}

ASHRAE. 1993. Fundamentals Handbook. American Society of Heating, Refrigerating and Air-Conditioning Engineers, Inc. Atlanta.

ASTM. 1992. Standard Test Method for Determining Air Leakage Rate by Fan Pressurization. E779-87 (1992). American Society for Testing and Materials. Philadelphia.

Burch, D.M.,W.E. Remmert, D.F. Krintz, and C.S. Barnes. 1982. "A Field Study of the Effect of Wall Mass on the Heating and Cooling Loads of Residential Buildings." Proceedings of the Building Thermal Mass Seminar, Knoxville, TN

Hodgson, A.T., J.M. Daisey, and F.J. Offermann. 1990. "A Sampling and Analytical Method for Gas-Phase Polycyclic Aromatic Hydrocarbons in Indoor Air.” Fifth International Conference on Indoor Air Quality and Climate, Indoor Air '90. Toronto. pp. 719-723.

Knight, C.V. and M.P. Humphreys. 1985. "Impacts of Airtight and Nonairtight Wood Heaters on Indoor Levels of Polynuclear Aromatic Hydrocarbons in a Weatherized Home." Tenth International Symposium on Polynuclear Aromatic Hydrocarbons. Columbus, Ohio. pp. 461-476.

Knight, C.V., M.P. Humphreys, and J.C. Pinnix. 1986. "Indoor Air Quality Related to Wood Heaters." IAQ'86 Managing Indoor Air for Health and Energy Conservation. American Society of Heating, Refrigerating and Air-Conditioning Engineers, Inc. Atlanta. pp. 430-447.

Offermann, F.J., S.A. Loiselle, A.T. Hodgson, L.A. Gundel, and J.M. Daisey. 1994. “A Pilot Study to Measure Indoor Concentrations and Emission Rates of Polycyclic Aromatic Hydrocarbons." Indoor Air. Vol. 4. pp. 497-512.

Sharpless, K.S. and S.A Wise. 1994. "Liquid Chromatographic Determination of Polycyclic Aromatic Hydrocarbons in Woodstove Indoor Emissions." Report of Analysis 835-94-092, Organic Analytical Research Division, Chemical Science and Technology Laboratory, National Institute of Standards and Technology, Gaithersburg, MD.

Sheldon, L., A. Clayton, R. Perritt, D.A. Whitaker, and J. Keever. 1993a. "Indoor Concentrations of Polycyclic Aromatic Hydrocarbons in California Residences and Their Relationship to Combustion Source Use." 6th International Conference on Indoor Air Quality and Climate, Indoor Air '93. Helsinki, Finland. pp, 29-34.

Sheldon, L., A. Clayton, J. Keever, R. Perritt, and D. Whitaker. 1993b. "Indoor Concentrations of Polycyclic Aromatic Hydrocarbons in California Residences." Research Triangle Institute. RTI Contract Number: 321U-5038/010-3F.

Traynor, G.W., D.W. Anthon, and C.D. Hollowell. 1982. "Technique for Determining Pollutant Emissions from a Gas-Fired Range.” Atmospheric Environment. Vol. 16. pp. 2979-2987.

Traynor, G.W, M.G. Apte, A.R. Carruthers, J.F. Dillworth, D.T. Grimsrud, and L.A. Gundel. 1987. "Indoor Air Pollution due to Emissions from Wood-Burning Stoves." Environmental Science \& Technology. Vol. 21.pp. 691-697.

Wilson, N.K, J.C. Chuang, and M.R. Kuhlman. 1991. "Sampling Polycyclic Aromatic Hydrocarbons and Related Semivolatile Organic Compounds in Indoor Air." Indoor Air. Vol. 4. pp. 513-521. 


\section{ACKNOWLEDGEMENTS}

This work was sponsored by the U.S. Consumer Product Safety Commission under Interagency Agreement No. CPSC-IAG-93-1125. The authors wish to acknowledge the efforts of Michael Babich of CPSC in support of this project. The authors also wish to express their gratitude to E.D. Chikhliwala of EcoChem for loaning the real-time PAH monitor. The efforts of Susannah Schiller of the Statistical Engineering Division of NIST in performing the statistical analysis of the data are also acknowledged as a significant contribution to this effort. The authors also express their appreciation to W. Stuart Dols, Kent Holguin, Huynh Luu, and Doug Pruitt for their efforts in conducting the tests and analyzing the data, and to Lucy Poole and Robin Rodenhauser for their assistance in preparing the report. 



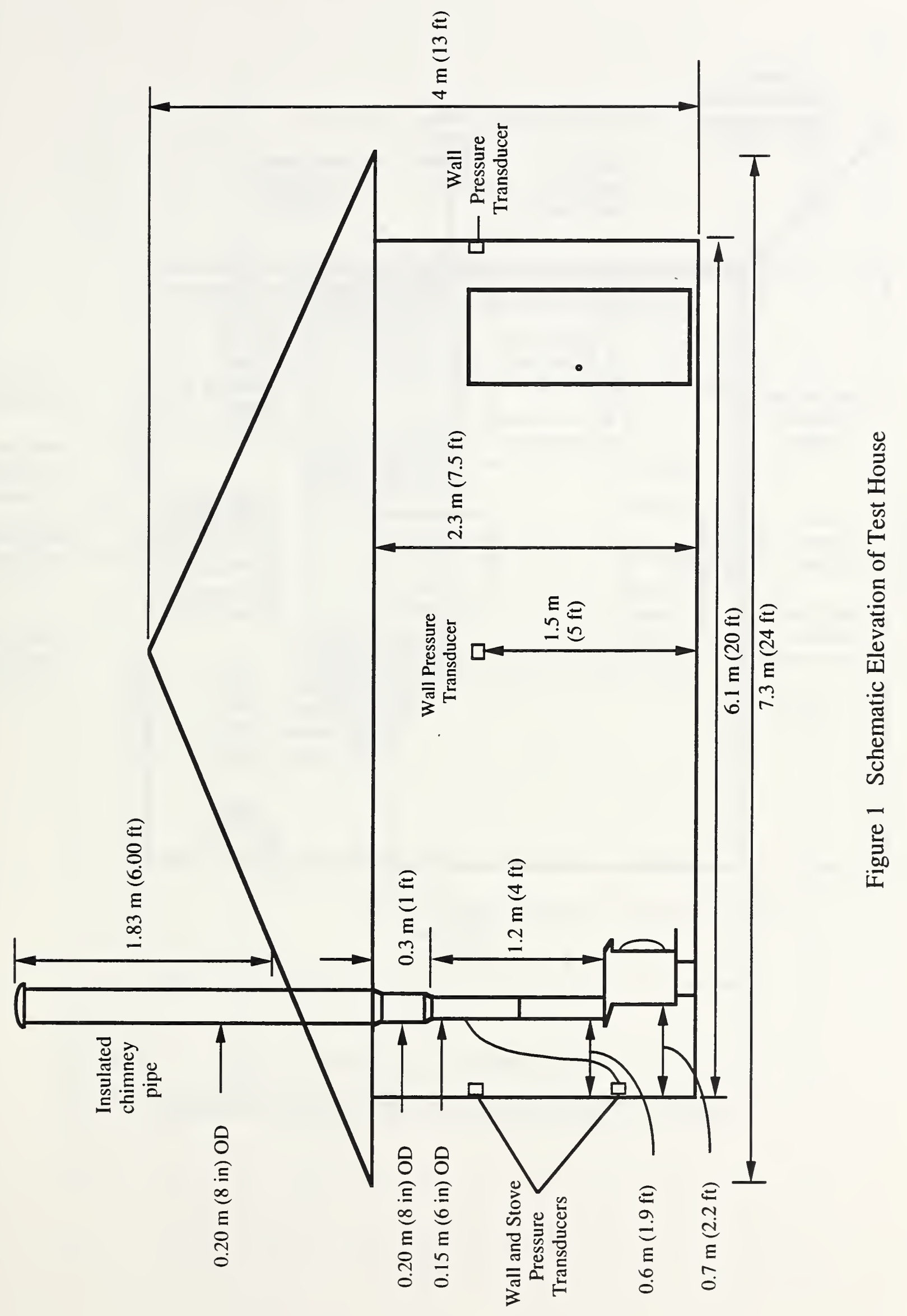






Figure 2 Floorplan Showing Location of Instrumentation 


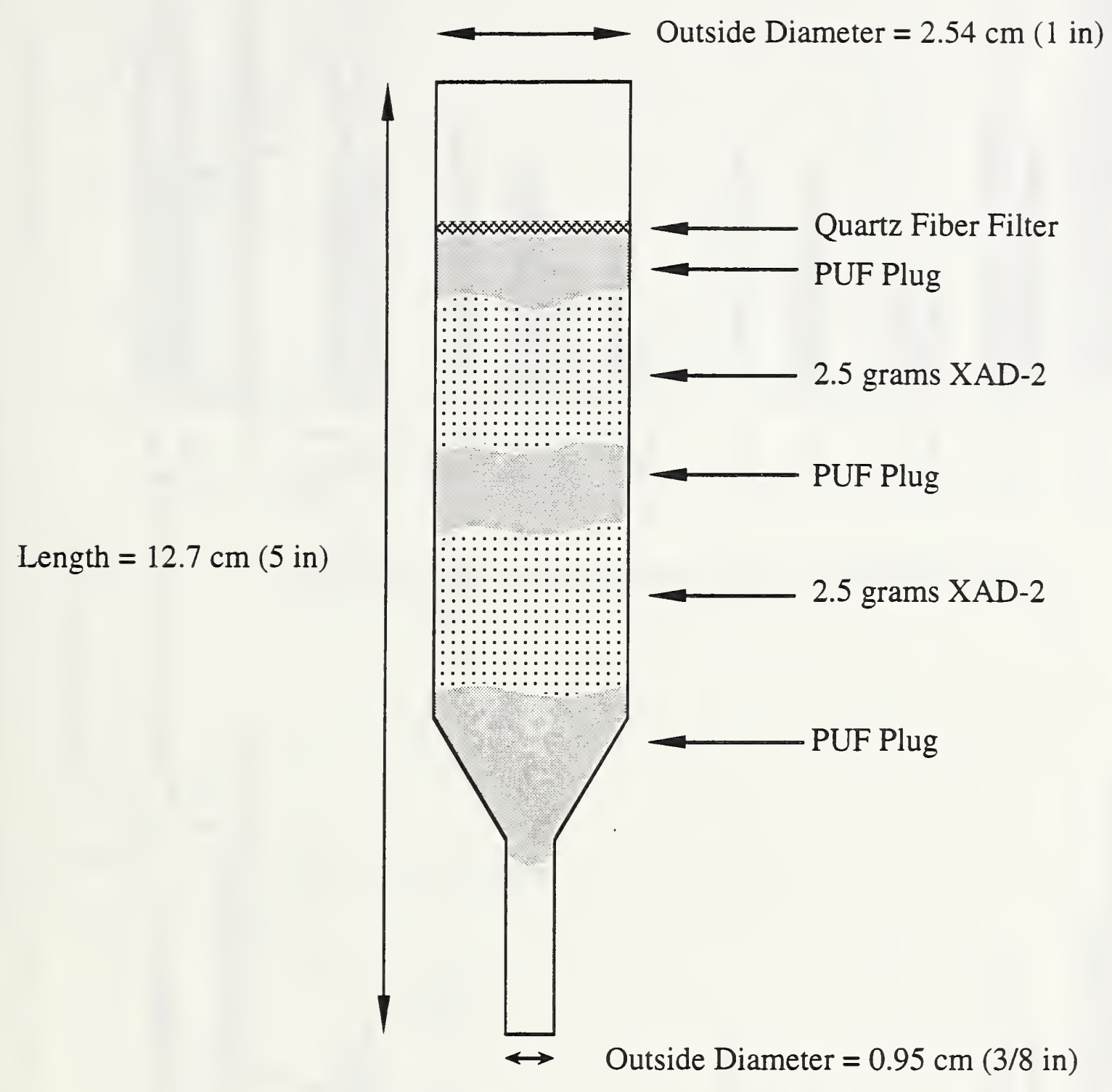

Figure 3 Schematic of Sorbent Tube 


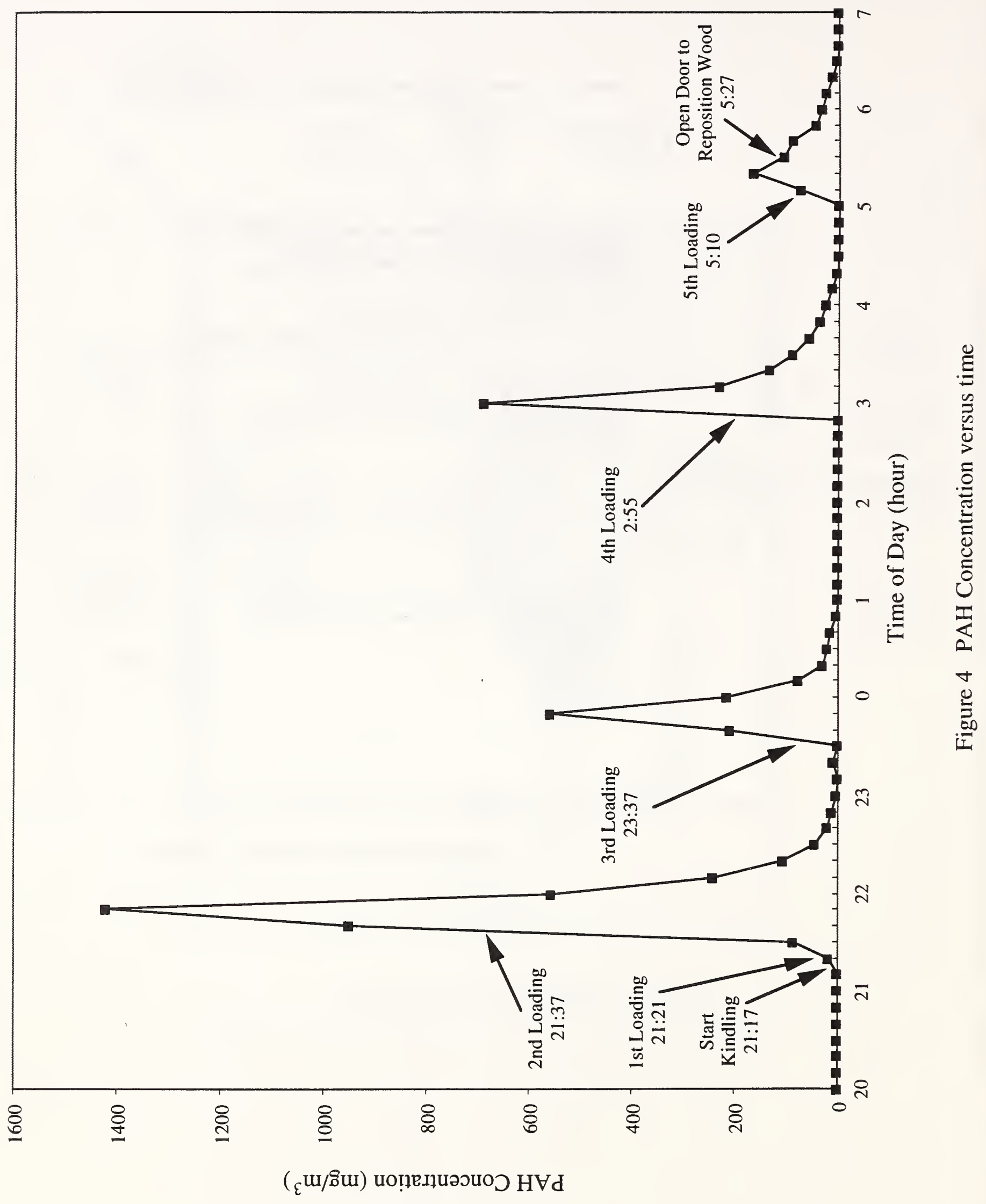




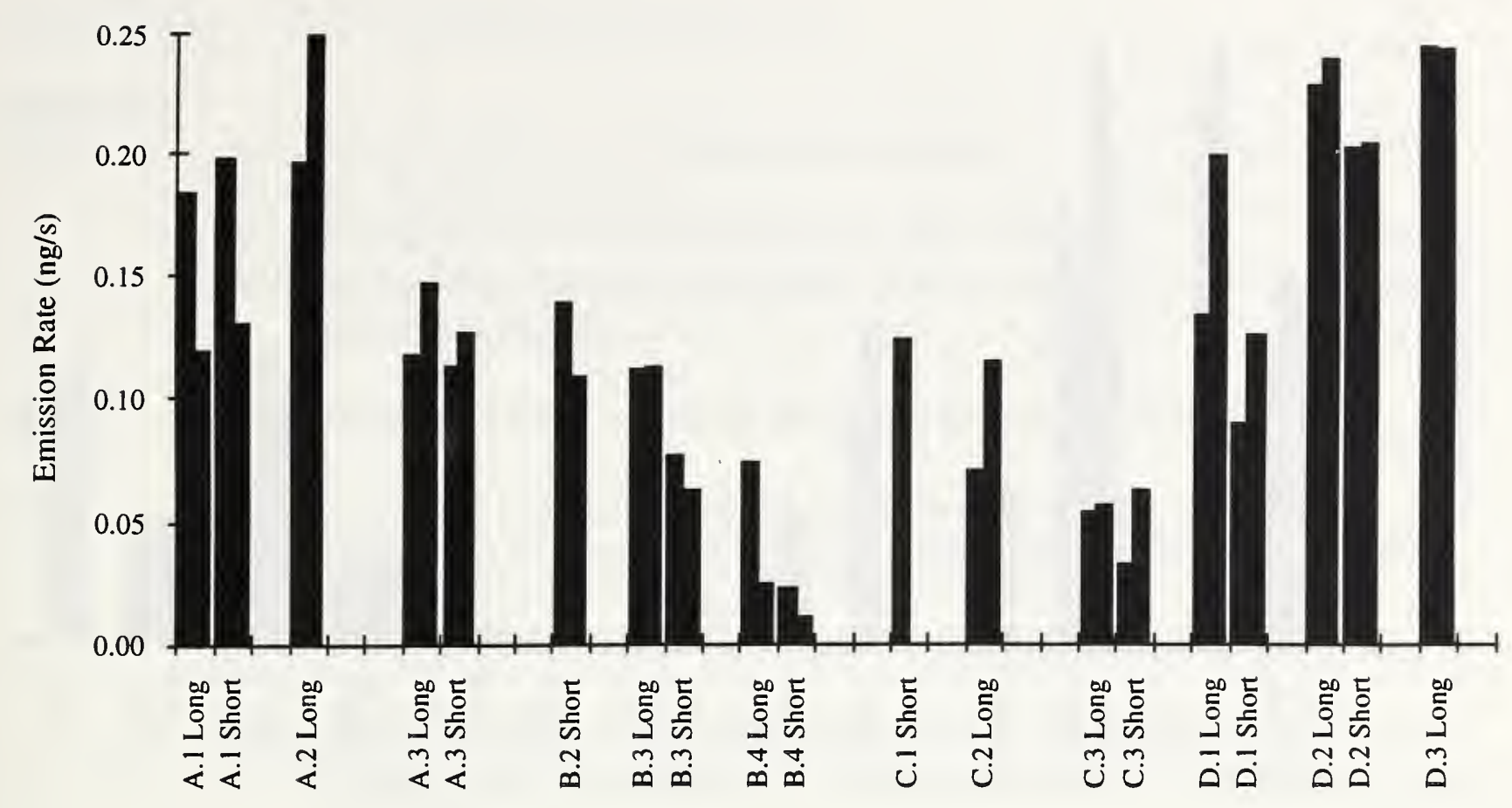

Figure 5 Total PAH Emission Rate for Individual Tests



Figure 6 Total PAH Source Strength Relative to Wood Consumption for Individual Tests 


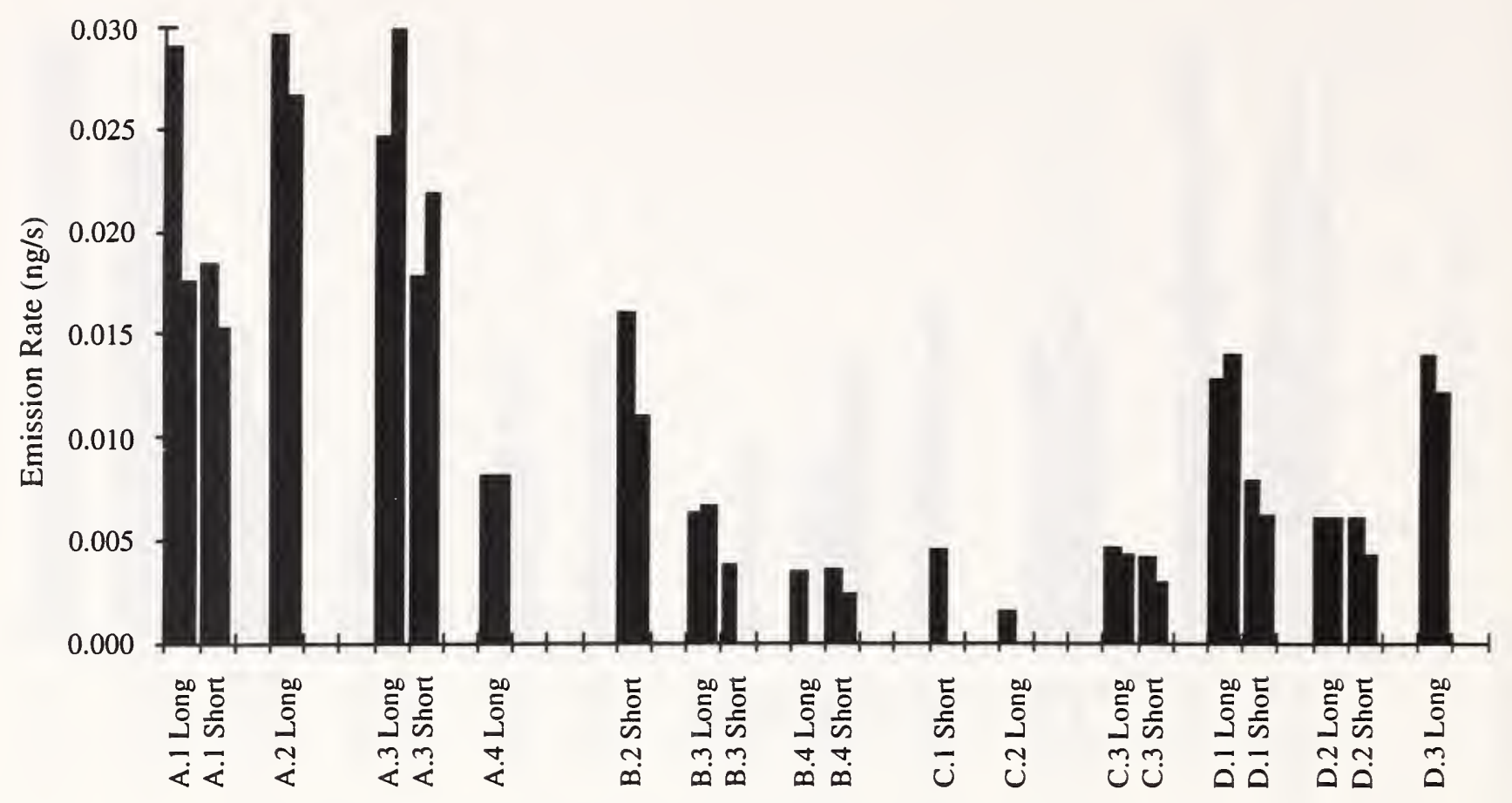

Figure $7 \mathrm{BaP}$ Emission Rate for Individual Tests

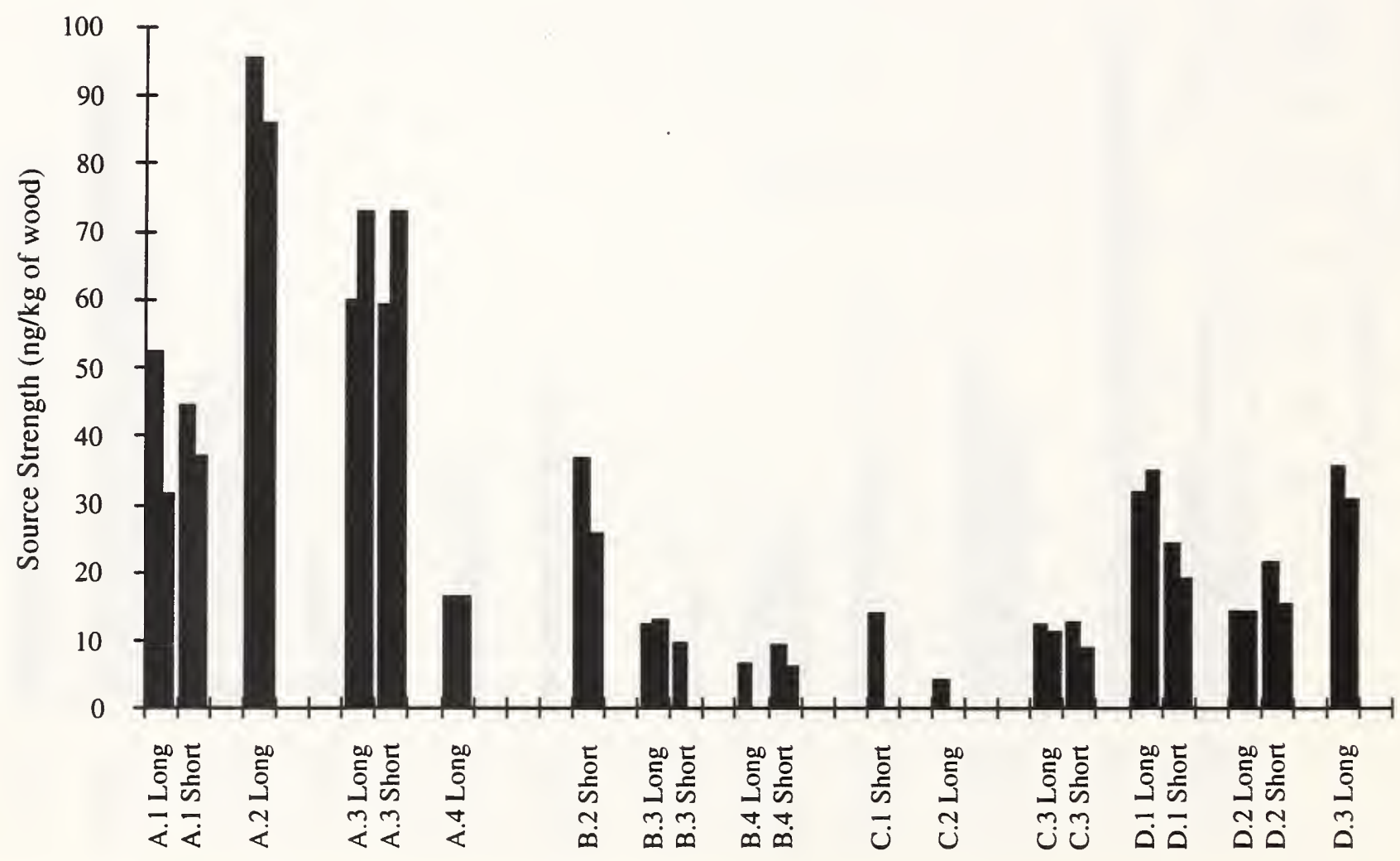

Figure 8 BaP Source Strength Relative to Wood Consumption for Individual Tests 


\section{APPENDIX A STOVE OPERATION PROTOCOL}

\section{Preparation}

Wood

Furnace

Stove
Day Before: Split one piece of wood for kindling.

Number 12 pieces of wood.

Weigh each piece of wood and record weight in notebook.

Measure moisture content of each piece of wood; measure in four places and record each reading.

Set thermostat at $15^{\circ} \mathrm{C}$ (about $60^{\circ} \mathrm{F}$ ) and set fan on continuous operation.

Open stove vent and catalytic converter (if present) all the way.

Put 3 fire starters in stove, light them and put kindling on fire.

Close door.

Record time and room temperature from the tracer gas system.

When fire is burning well: slowly open the door $1.5 \mathrm{~cm}$ (about $1 / 2 \mathrm{in}$ ) for 10 seconds; then slowly open the door completely, add full load of wood and close door.

Record numbers of the wood pieces, time, stove temperature and room temperature from tracer gas system.

When stove temperature reaches $200^{\circ} \mathrm{C}\left(400^{\circ} \mathrm{F}\right)$, close catalytic converter completely (if present) and partially close vent.

Record action and time.

\section{Stove Operation}

Gradually close stove vent to keep stove temperature at $200^{\circ} \mathrm{C}\left(400{ }^{\circ} \mathrm{F}\right)$ and house temperature between 21 and $27^{\circ} \mathrm{C}\left(70\right.$ and $\left.80^{\circ} \mathrm{F}\right)$ as displayed on the tracer gas system monitor.

Open vent when house temperature is below $21^{\circ} \mathrm{C}\left(70^{\circ} \mathrm{F}\right)$.

Close vent when house temperature is above $27^{\circ} \mathrm{C}\left(80^{\circ} \mathrm{F}\right)$.

Whenever the vent is adjusted, record the vent adjustment, time, stove temperature and room temperature from the tracer gas system.

When wood is down to one-quarter of the stove capacity: open the stove vent; slowly open the door $1.5 \mathrm{~cm}$ (about $1 / 2$ in) for 10 seconds; then slowly open the door completely.

Gently rake the coals (if necessary) and reload stove to full capacity.

Close the stove door.

Record numbers of the wood pieces, time, stove temperature and room temperature from tracer gas system.

If the stove temperature drops below $150^{\circ} \mathrm{C}\left(350^{\circ} \mathrm{F}\right)$, open the catalytic converter and record action, time and stove temperature.

When stove temperature rises above $200^{\circ} \mathrm{C}\left(400^{\circ} \mathrm{F}\right)$, close the catalytic converter and record action, time and stove temperature. 
When stove temperature rises above $200^{\circ} \mathrm{C}\left(400^{\circ} \mathrm{F}\right)$ or the room temperature rises above $27^{\circ} \mathrm{C}\left(80^{\circ} \mathrm{F}\right)$, gradually close the vent.

Whenever the vent is adjusted, record the vent adjustment, time, stove temperature and room temperature from the tracer gas system.

Shut Down

Stove When test is complete, open catalytic converter and stove vent.

Furnace Turn thermostat up to $21^{\circ} \mathrm{C}\left(70^{\circ} \mathrm{F}\right)$.

Clean Up (Day after test)

Stove Remove ash tray and take outside house.

Empty ashes into ash bucket outside of house, leaving a bed of about 3 to $5 \mathrm{~cm}$ (1 or 2 in) in tray.

Replace ash tray in stove.

House Reorganize and restock wood pile.

Sweep and wet-mop floor. 


\section{APPENDIX B INSTRUMENTATION PROTOCOL}

The following protocol is organized with reference to the various data collection systems and instruments used in the tests. $\mathrm{SF}_{6}$ refers to the automated tracer gas decay system. $\mathrm{CO} / \mathrm{CO}_{2}$ refers to the automated system used to monitor carbon monoxide and carbon dioxide concentrations. DAS refers to the PC-based data acquisition system used to monitor the output of the real-time PAH monitor and the pressures across the walls and in the flue. C-PC refers to the real-time particle counter. PM10 refers to the pumps and impactors to determine average particle mass over the designated sampling periods. PAH refers to the pumps and sorbent tubes used to monitor average PAH concentrations over the sampling periods.

\section{Preparation}

$\mathrm{SF}_{6}$

$\mathrm{CO} / \mathrm{CO}_{2}$

DAS

C-PC

PM10
Record in $\mathrm{SF}_{6}$ notebook: $\mathrm{P}-5$ cylinder pressure, base frequency, $\mathrm{SF}_{6}$ peak time, base adjust, column temperature, detector temperature and sample flow rate.

Check airflow rate at outlets of all air sampling pumps; check back of $\mathrm{SF}_{6}$ monitor to make sure the inlet lines are connected.

Check visually: outdoor concentrations between 0 and $1 \mathrm{ppb}$; indoor concentrations within $2 \mathrm{ppb}$ of each other; values of indoor ach within $10 \%$ range. Record any deviations in $\mathrm{SF}_{6}$ notebook.

Check visually: program is running; outdoor $\mathrm{CO}_{2}$ concentrations are between 350 and $400 \mathrm{ppm}$ and indoor concentrations within $25 \mathrm{ppm}$ of each other; outdoor $\mathrm{CO}$ concentrations between 2 and $5 \mathrm{ppm}$ and indoor concentrations within $1 \mathrm{ppm}$ of each other. Record any deviations in MISC notebook.

Check back of $\mathrm{CO}_{2}$ case to make sure inlet lines are connected.

Check visually: PAH level between 0 and $5 \mathrm{ng} / \mathrm{m}^{3}$; wall pressure transducer outputs between 2.4 and 2.6 volts.

Check visually to make sure the monitor's display is counting and that the last particle count is on PC screen.

Fill soap-film pump calibrator with soap solution.

Turn on both pumps and keep black case closed.

Connect Pump \#1 tubes for indoor samples and Pump \#2 tubes for outdoor samples.

Push in timer tabs for continuous operation and set time-share at 20 minutes.

Set Pump \#1 at 8.50 on pot (4.58 volts) and Pump \#2 at 7.90 on pot (4.40 volts).

Connect 2-conductor lines to the voltage output of both pumps for checking during test.

Select four filter cassettes: indoor long, indoor short, outdoor long, and outdoor short; record cassette numbers with sample location/duration, pump number and pump tube in PM10/PAH notebook. 
PAH Select seven PAH tubes: 2 indoor long term; 2 indoor short term; 1 outdoor long term; 1 outdoor short term; 1 field blank. Record tube numbers with sample location/duration in PM10/PAH notebook.

Set up sampling stands at indoor and outdoor sample locations, run inlet tubes from stands to pumps, and connect inlet tubes to pumps.

Connect exhaust lines to pumps and run lines outside of test house.

Place all PAH tubes at corresponding air sampling pump and turn on all 6 pumps.

Set pump airflow rates per individual pump calibration; record airflow rate setting for each pump in PM10/PAH notebook.

Long Sample Start-Up (Prior to starting stove)

PM10 Apply mineral oil to all four impactor plates and install plates and filters in impactors.

Mount outdoor/short and long impactors on outdoor bracket.

Turn off Pump \#1.

Record initial elapsed time of time share box (black) and initial time from mass flow controller box (green) for Pump \#1.

Connect indoor/long impactor to Pump \#1 long tube, turn on Pump \#1 and record time and DC voltage from pump.

Turn off Pump \#2.

Record initial elapsed time of time share box (black) and initial time from mass flow controller box (green) for Pump \#2.

Connect outdoor/long impactor to Pump \#2 long tube, turn on Pump \#2 and record time and DC voltage from pump.

$\mathrm{PAH} \quad$ Turn on and set pump airflow rates per individual pump calibration; record airflow rate setting for each pump in PM10/PAH notebook.

Connect indoor/long and outdoor/long sorbent tubes to air sampling pumps; record sorbent tube and pump numbers, location/duration (long or short) and time.

\section{DO NOT TOUCH SORBENT TUBES OR INNER FOIL SURFACE WITH FINGERS, WEAR GLOVES}

Short Sample Start-Up (After second loading of stove)

PM10 Connect indoor/short impactor to Pump \#1 short tube when the pump is pulling on indoor/long impactor.

Record time, DC voltage from pump, elapsed time of time share box and time from mass flow controller for Pump \#1.

Connect outdoor/short impactor to Pump \#2 short tube when the pump is pulling on outdoor/long impactor.

Record time, DC voltage from pump, elapsed time of time share box and time from mass flow controller for Pump \#2.

PAH Reset pump airflow rates per individual pump calibration; record airflow rate setting for each pump in PM10/PAH notebook.

Connect indoor/short and outdoor/short sorbent tubes to air sampling pumps; record tube numbers, location/duration and time.

DO NOT TOUCH SORBENT TUBES OR INNER FOIL SURFACE WITH FINGERS, WEAR GLOVES 
First Mid-Test Check (roughly 1 hour after starting short samples)

$\mathrm{SF}_{6} \quad$ Check and record in $\mathrm{SF}_{6}$ notebook: base frequency, $\mathrm{SF}_{6}$ peak time.

Check visually: outdoor concentrations between 0 and $1 \mathrm{ppb}$; indoor

concentrations within $2 \mathrm{ppb}$ of each other; values of indoor ach within $10 \%$ range.

Connect 10, 50, 100 and $200 \mathrm{ppb}$ calibration bags to extra GC port; record time, bag concentration and GC concentration in notebook.

$\mathrm{CO} / \mathrm{CO}_{2} \quad$ Check visually: outdoor concentrations between 350 and $400 \mathrm{ppm}$; indoor concentrations within $25 \mathrm{ppm}$ of each other; clock is running.

Connect zero, 350 and $1029 \mathrm{ppm} \mathrm{CO}_{2}$ calibration bags and 4 and $10 \mathrm{ppm} \mathrm{CO}$ calibration bags to extra outdoor port; record time, bag concentration and $\mathrm{CO}_{2}$ or $\mathrm{CO}$ concentration in MISC notebook.

DAS Check visually: PAH level, not after a recent stove door opening, between 0 and $50 \mathrm{ng} / \mathrm{m}^{3}$; wall pressure transducer outputs between 2.4 and 2.6 volts.

C-PC Check visually to make sure the monitor's display is counting and that the last particle count is on PC screen.

PM10 Record DC voltages for both pumps in PM10/PAH notebook.

PAH Check airflow rate on all 6 pump exhausts with soap-film calibrator; record 10 airflow rate readings, pump number and time in PM10/PAH notebook.

Second Mid-Test Check (about 4 hours after start of short samples)

$\mathrm{SF}_{6} \quad$ Check and record in $\mathrm{SF}_{6}$ notebook: base frequency, $\mathrm{SF}_{6}$ peak time.

Check visually: outdoor concentrations between 0 and $1 \mathrm{ppb}$; indoor concentrations within $2 \mathrm{ppb}$ of each other; values of indoor ach within $10 \%$ range.

$\mathrm{CO} / \mathrm{CO}_{2} \quad$ Check visually: outdoor concentrations between 350 and $400 \mathrm{ppm}$; indoor concentrations within $25 \mathrm{ppm}$ of each other; clock is running.

DAS

Check visually: PAH level, not after a recent stove door opening, between 0 and $50 \mathrm{ng} / \mathrm{m}^{3}$; wall pressure transducer outputs between 2.4 and 2.6 volts.

C-PC Check visually to make sure the monitor's display is counting and that the last particle count is on PC screen.

PM10 Record DC voltages for both pumps in PM10/PAH notebook.

PAH Check airflow rate on all 6 pump exhausts with soap-film calibrator; record 10 airflow rate readings, pump number and time in PM10/PAH notebook. 
Sample Shut-Down

PM10 Turn off pumps 1 and 2.

Remove cassettes from all impactors and place in plastic holders; record time in PM10/PAH notebook.

Record final elapsed time of time share box and final time from mass flow controller for pumps 1 and 2 .

PAH Turn off all Gilian pumps.

Disconnect tubes, swab off bases with methylene chloride, wrap tubes in foil and place in glass bottles; record time in PM10/PAH notebook.

DO NOT TOUCH SORBENT TUBES OR INNER FOIL SURFACE WITH FINGERS, WEAR GLOVES

\section{$\underline{\text { Post Test }}$ \\ $\mathrm{SF}_{6}$}

Record in notebook: $\mathrm{P}-5$ cylinder pressure, base frequency, $\mathrm{SF}_{6}$ peak time Check visually: outdoor concentrations between 0 and $1 \mathrm{ppb}$; indoor concentrations within $2 \mathrm{ppb}$ of each other; values of indoor ach within $10 \%$ range.

$\mathrm{CO} / \mathrm{CO}_{2} \quad$ Check visually: outdoor concentrations between 350 and $400 \mathrm{ppm}$; indoor concentrations within $25 \mathrm{ppm}$ of each other

DAS Check visually: PAH level between 0 and $50 \mathrm{ng} / \mathrm{m}^{3}$; wall pressure transducer output is between 2.4 and 2.6 volts.

C-PC Check visually to make sure the monitor's display is counting and that the last particle count is on PC screen.

PM10 Unmount outdoor impactors and take inside.

Disassemble impactors and take impactor plates back to lab for cleaning.

Take cassettes back to lab for storage prior to shipment for analysis.

PAH Take outdoor sampling stands inside.

Take sorbent tubes back to lab for storage in refrigerator.

Non-Test Day

$\mathrm{SF}_{6}$

Check load time and peak separation; calibrate GC.

$\mathrm{CO} / \mathrm{CO}_{2} \quad$ Calibrate.

DAS Check zero of pressure gauges.

PM10 Calibrate both pumps and all four impactors at $10 \mathrm{~L} / \mathrm{min}$. 


\section{APPENDIX C TEST SUMMARY TABLES}

The following are the stove test summary tables previously described in the section on Test Results (page 12). This appendix includes a summary sheet on all acceptable stove tests. Each summary sheet contains the stove test ID number in the caption at the top. 


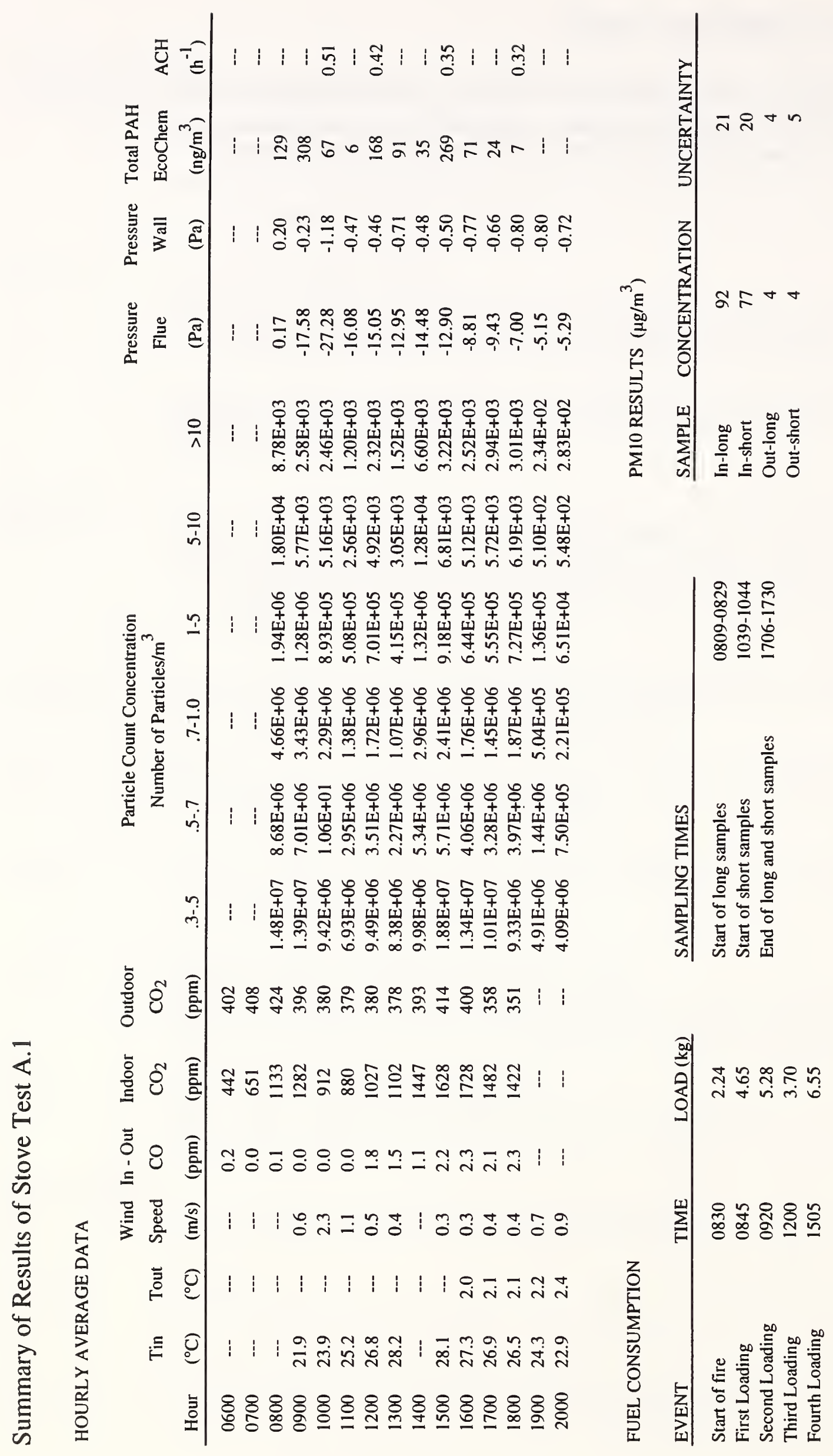




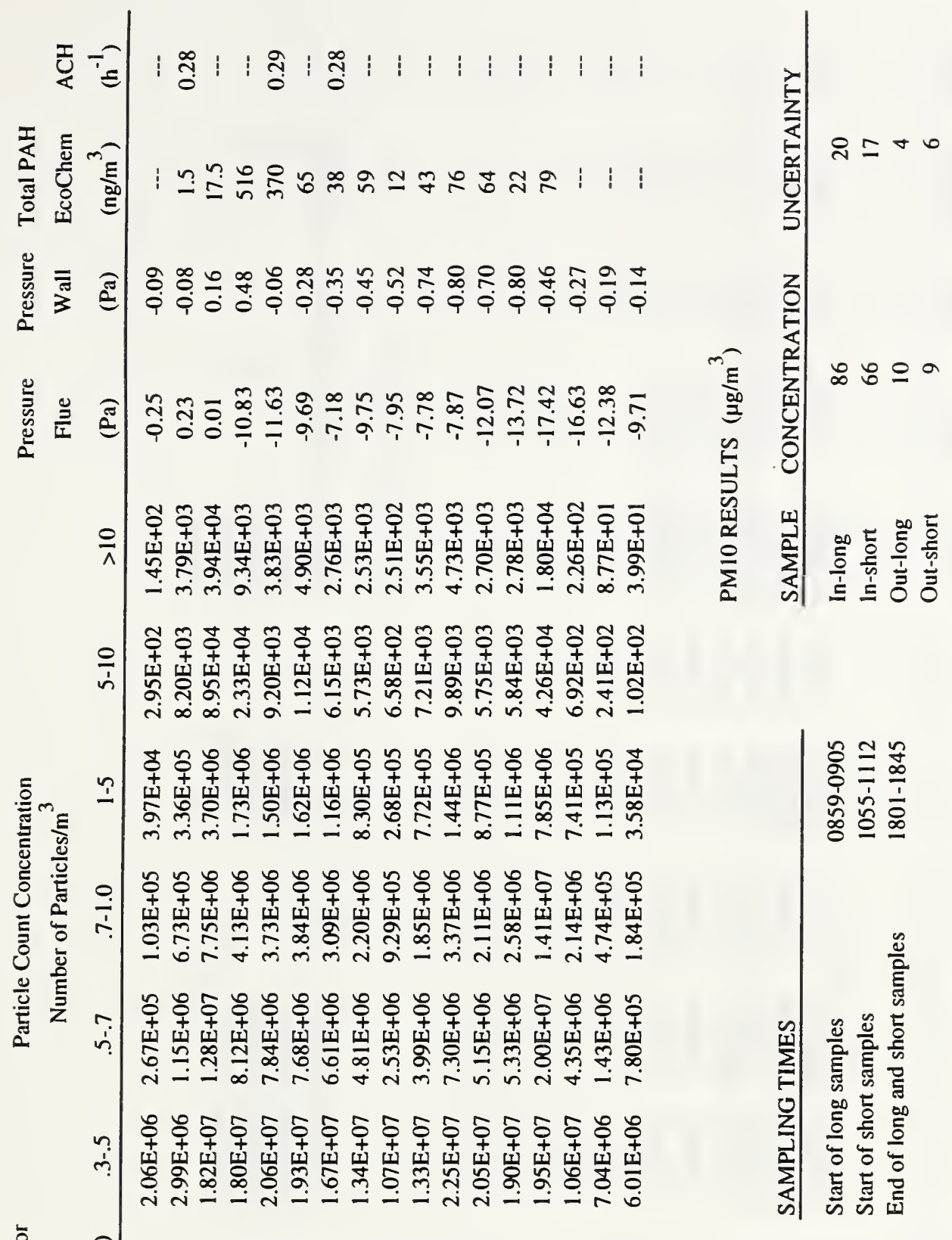

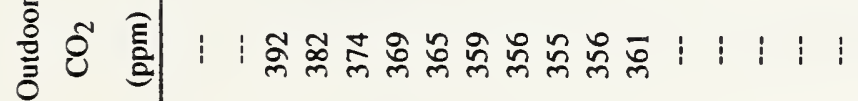

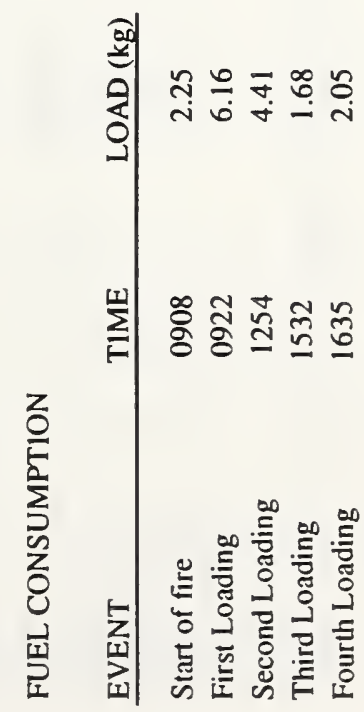









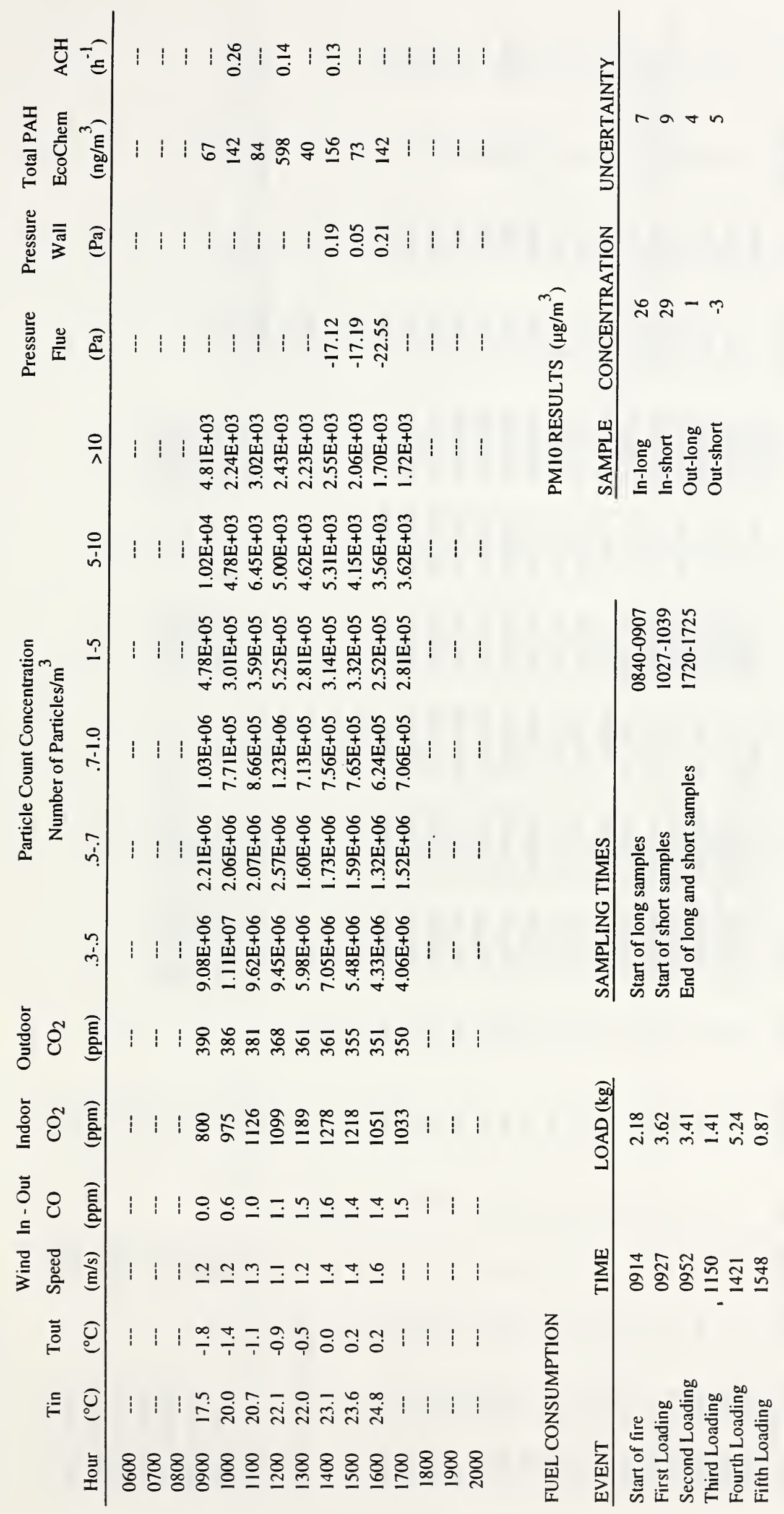




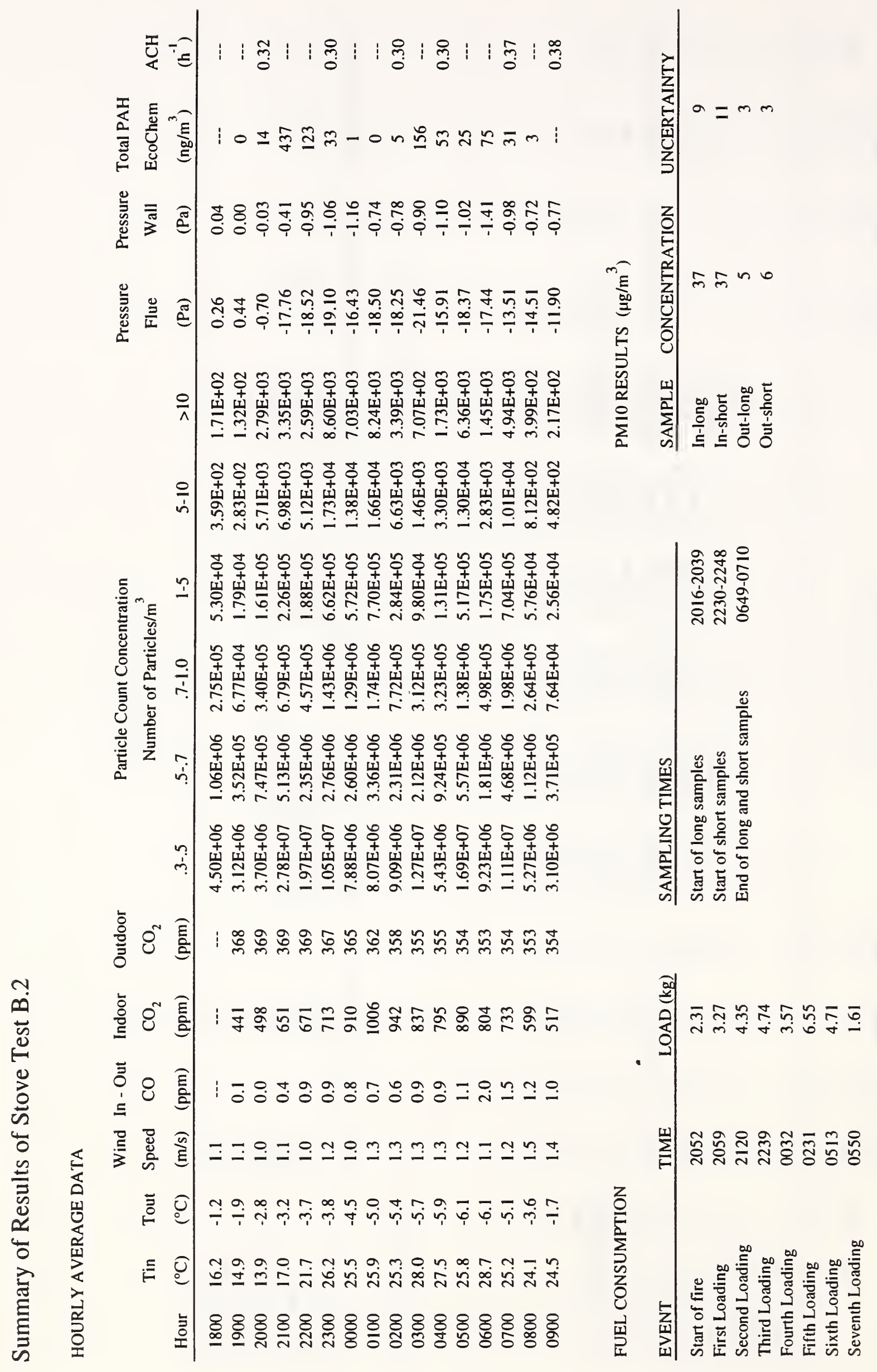









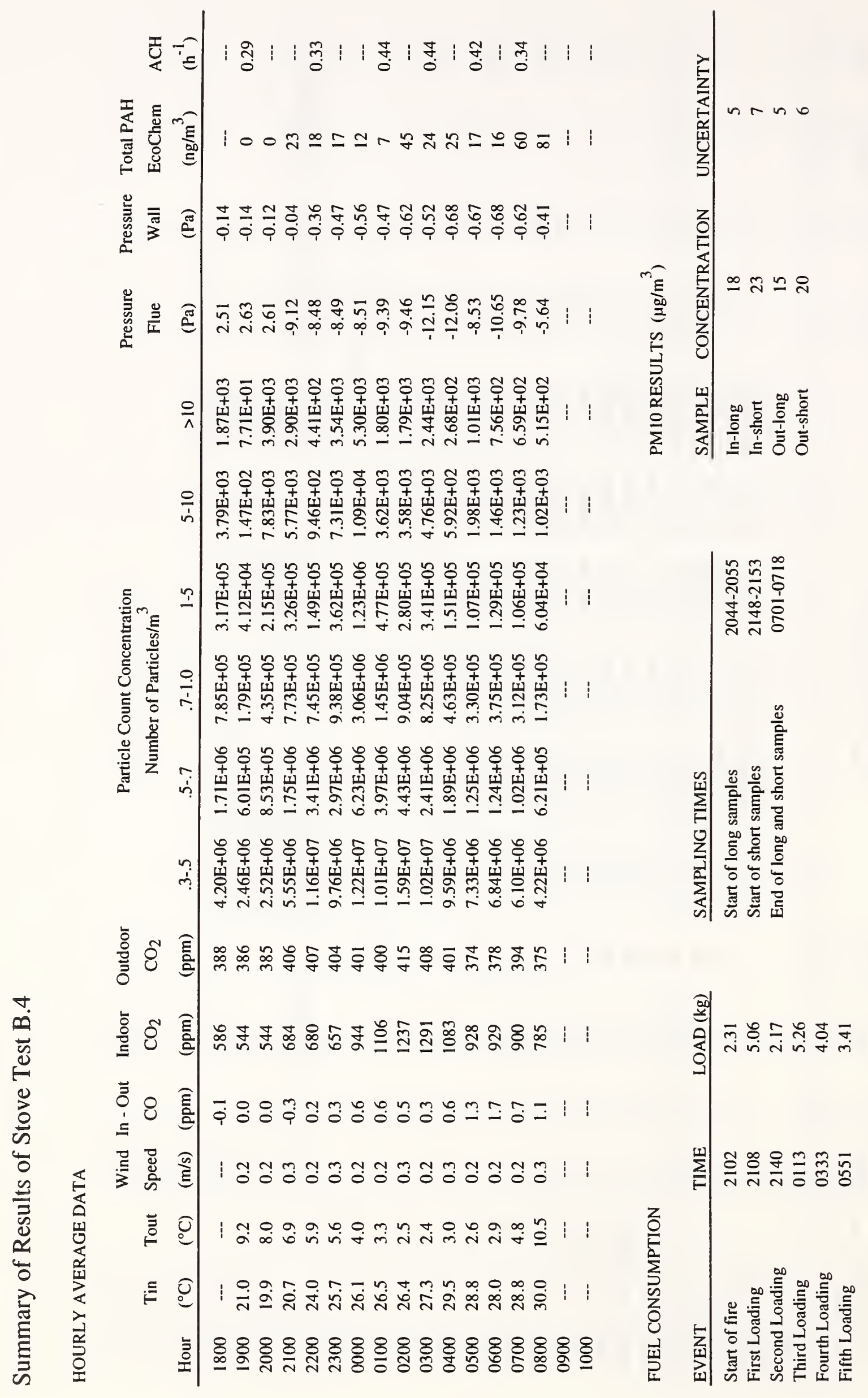









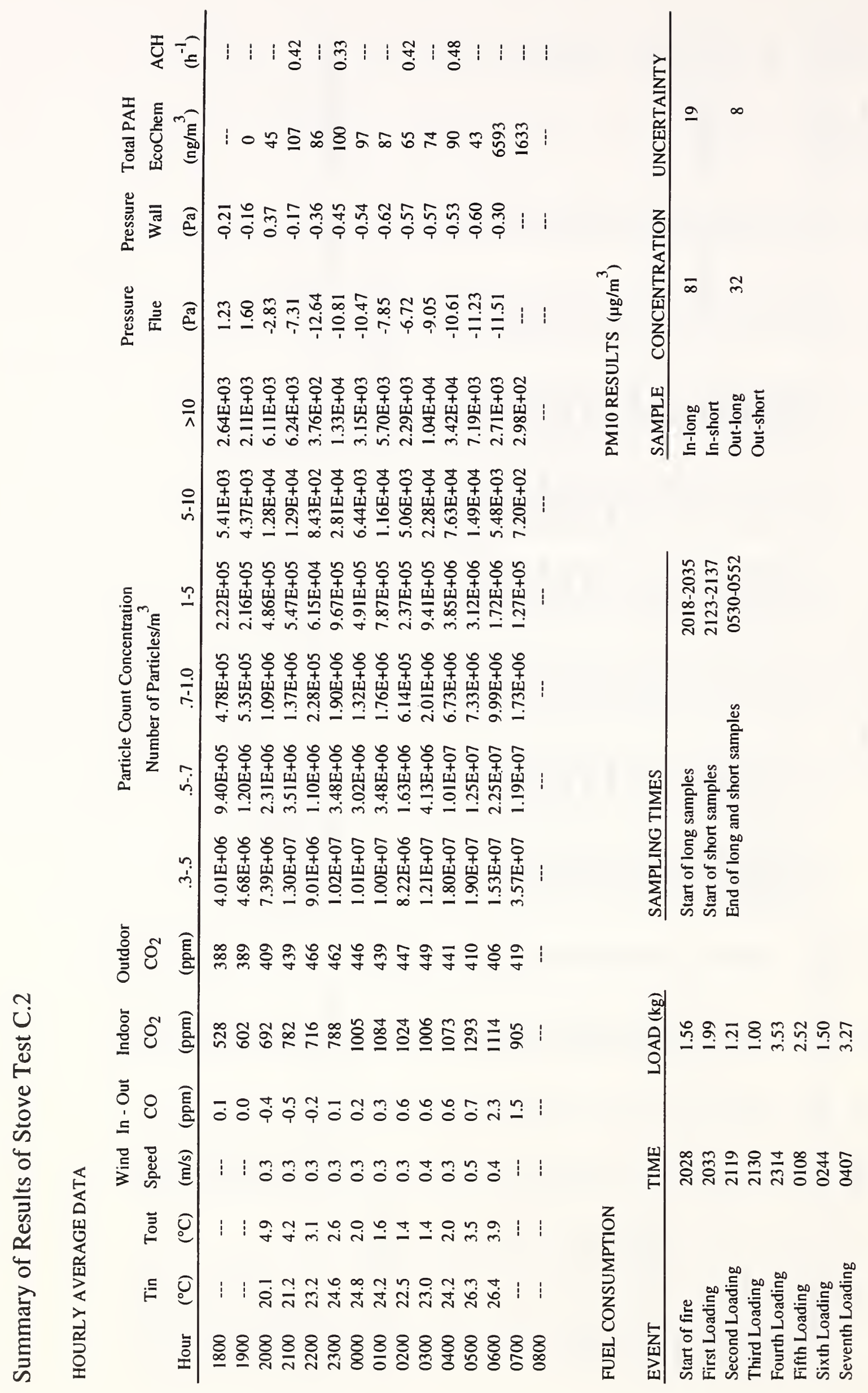




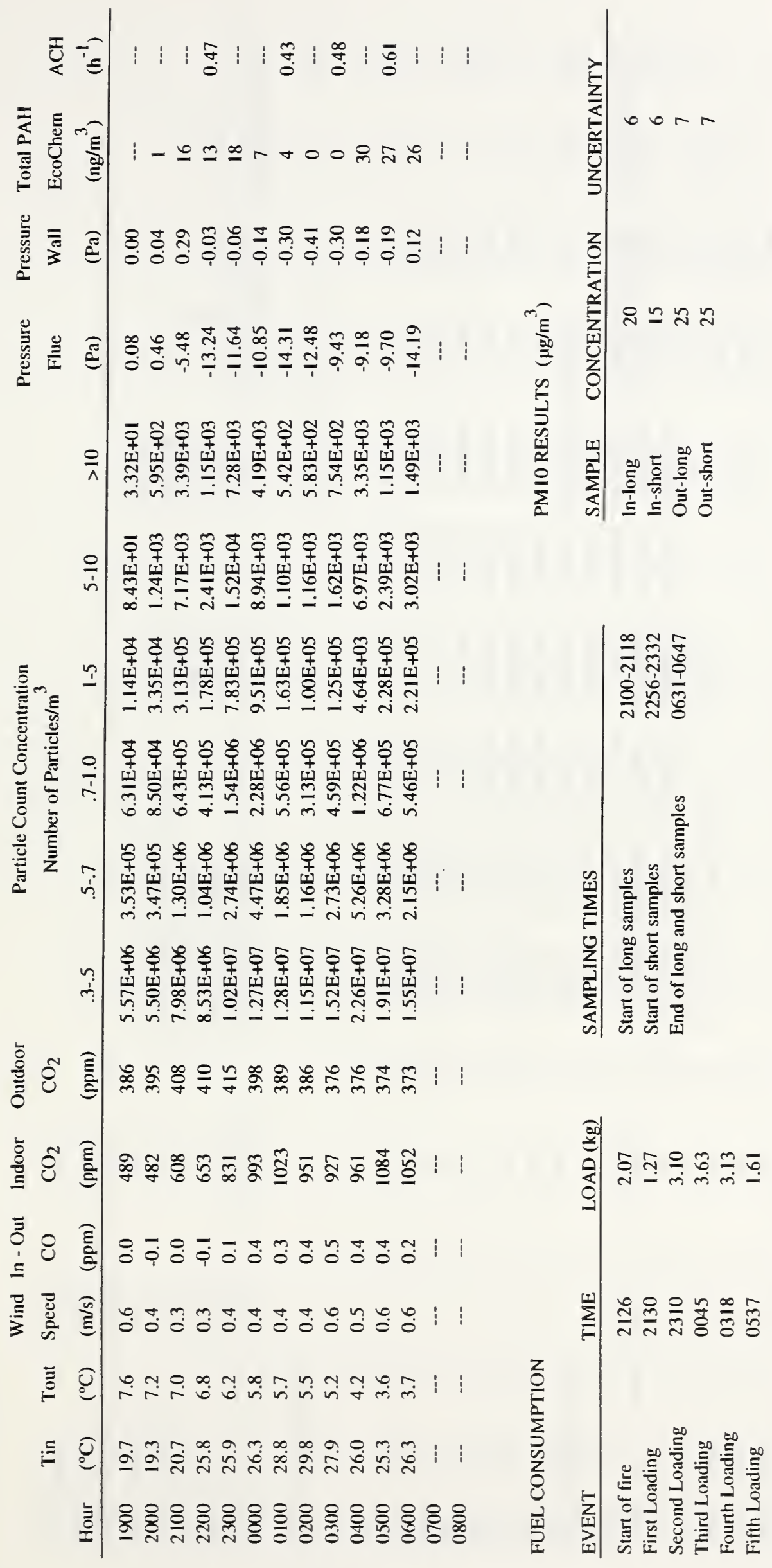




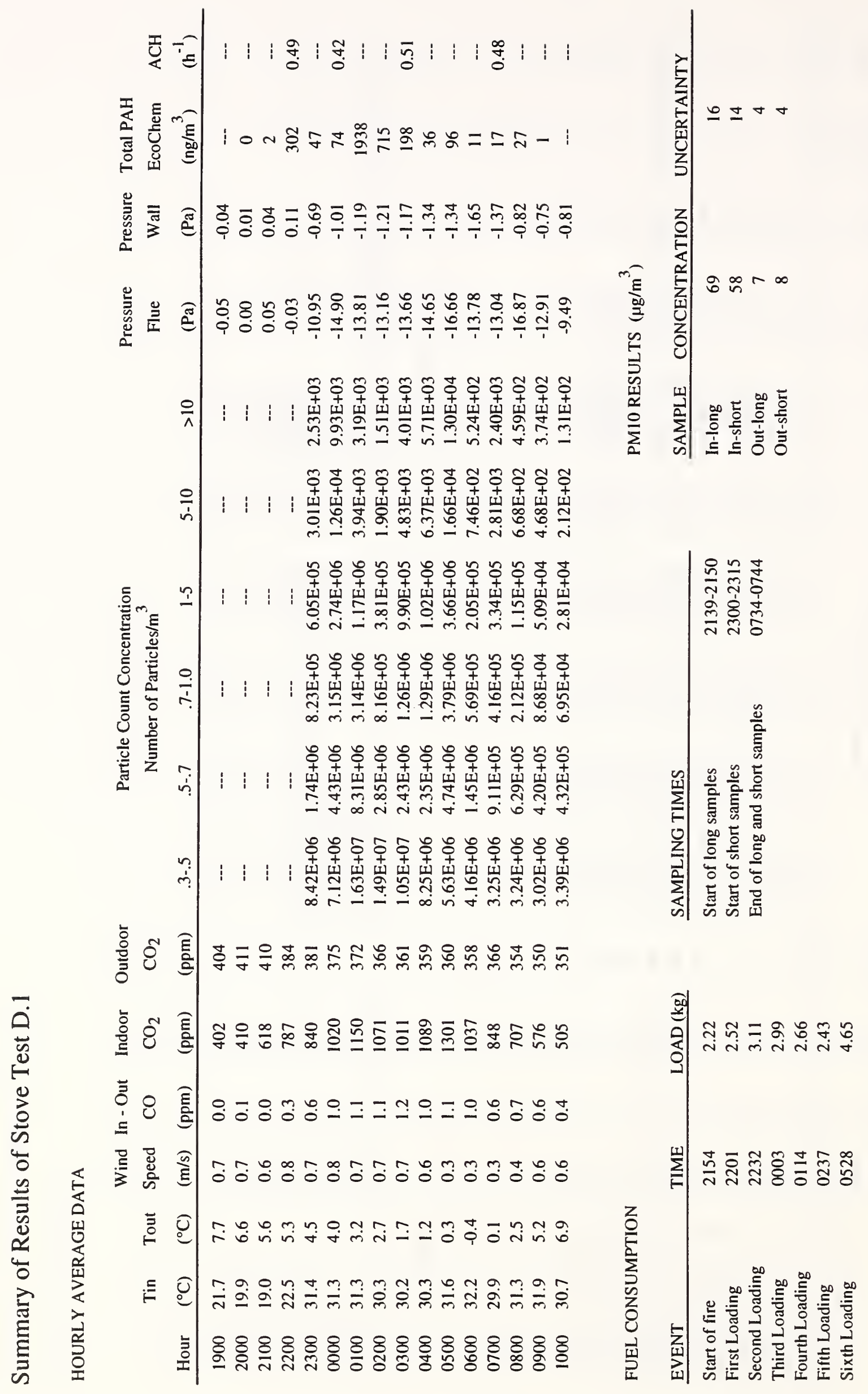




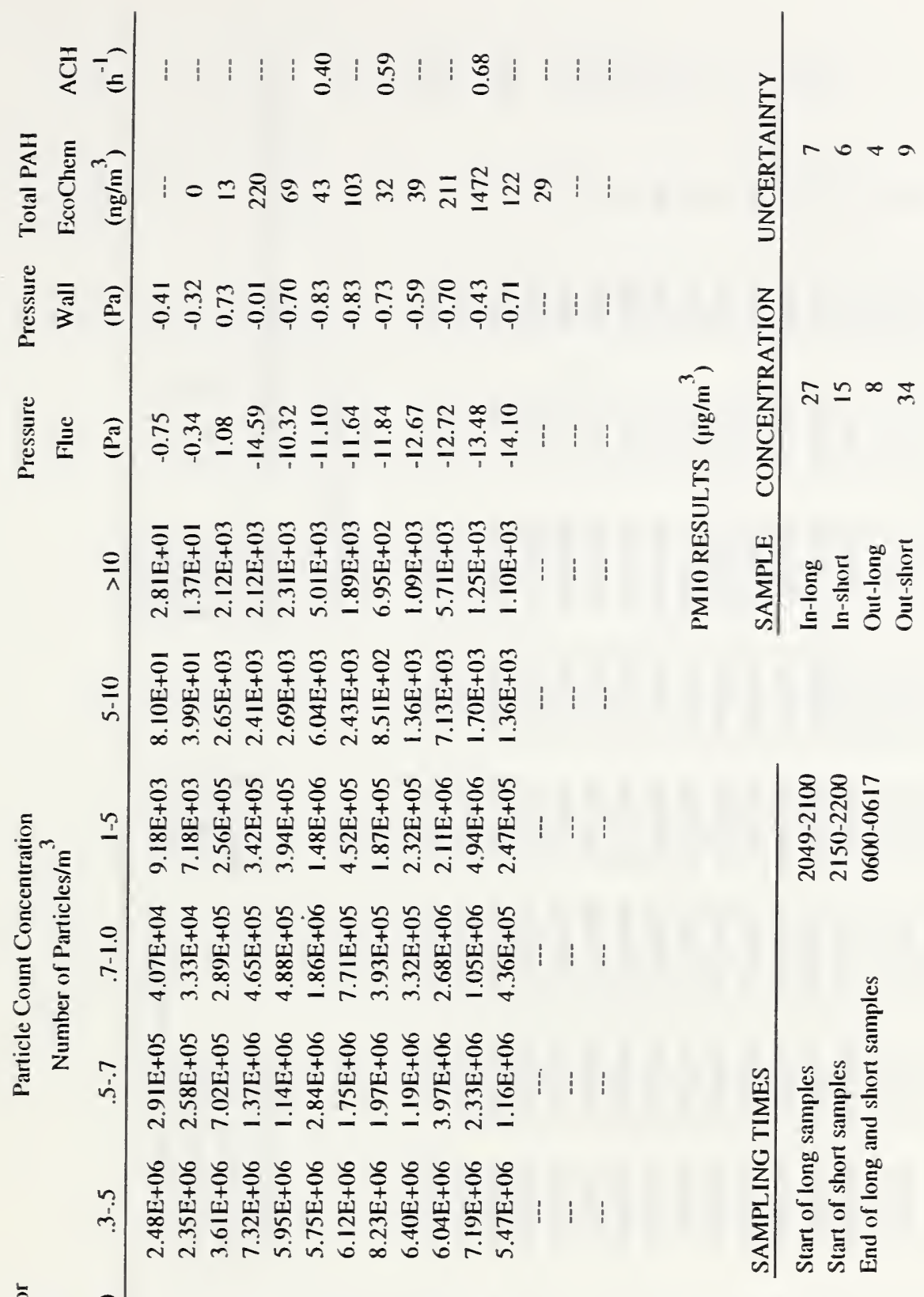

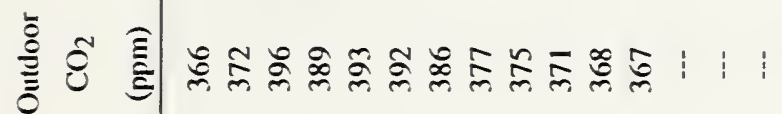

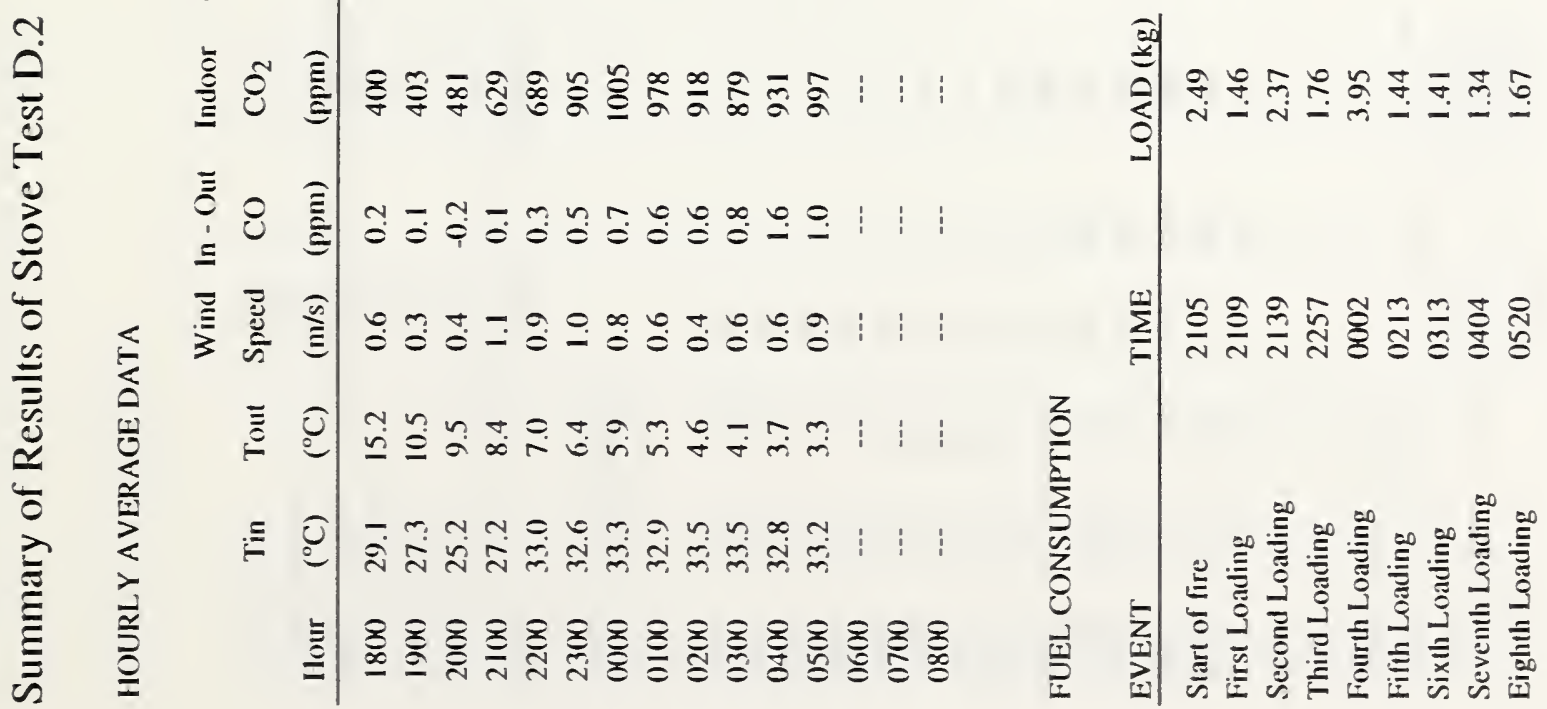









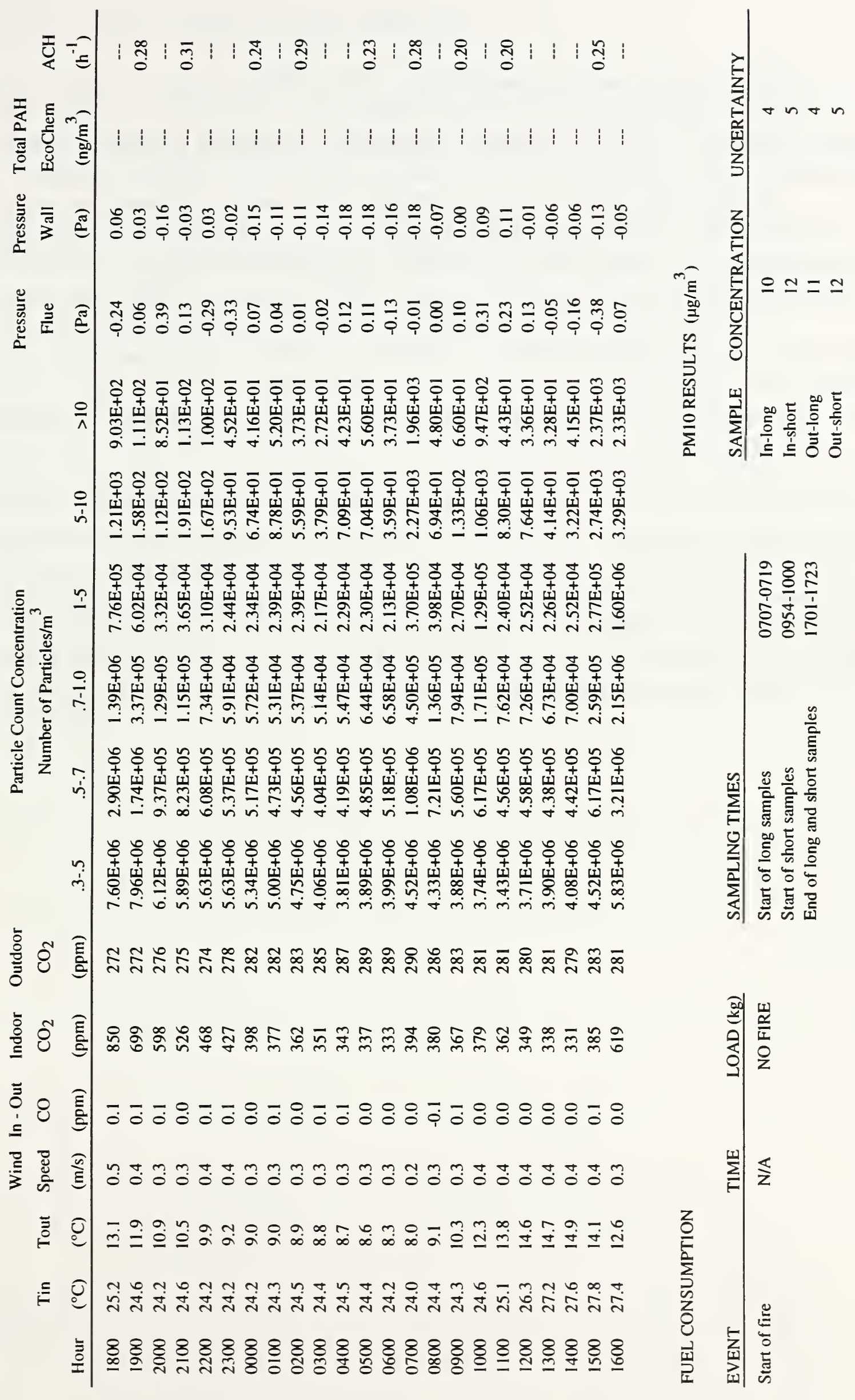




\section{APPENDIX D PAH CONCENTRATION RESULTS}

This appendix contains all of the PAH concentration measurement results from the sorbent tubes. The data in this table were obtained based on the analysis of these tubes performed by the Chemical Science and Technology Laboratory at NIST and contained in their Report of Analysis No. 835-94-092. The compound names corresponding to the concentration measurements have been abbreviated at the top of the columns. From left to right, the abbreviations and PAHs represented are: NAPHTH is naphthalene, PHEN is phenanthrene, ANTH is anthracene, FLUOR is fluoranthene, PYRENE is pyrene, $\mathrm{B}[\mathrm{a}] \mathrm{A}$ is benz[a]anthracene, CHRYS is chrysene, $\mathrm{PERY}$ is perylene, $\mathrm{B}[\mathrm{k}] \mathrm{F}$ is benzo[k]fluoranthene, $\mathrm{B}[\mathrm{a}] \mathrm{P}$ is benzo[a]pyrene, $\mathrm{DB}[\mathrm{a}, \mathrm{h}] \mathrm{A}$ is dibenz[a,h]anthracene, $\mathrm{B}$ [ghi]P is benzo[ghi]perylene, and INDENO is indeno[1,2,3-cd]pyrene. Tests A.2 and A.3 contain the results of breakthrough tests conducted at sample airflow rates of 20 and $15 \mathrm{~L} / \mathrm{min}$ respectively. The designations $\mathrm{D}$ and $\mathrm{U}$ correspond to the downstream and upstream sorbent tubes that were configured in series for these tests. If there was no breakthrough, the $\mathrm{D}$ tube would have collected no compounds. The designation $\mathrm{S}$ corresponds to the single sample duplicate of the upstream long and short test samples. The entries denoted with the symbol * correspond to negative concentration values after the mass on the blank sorbent tube was subtracted. Values of 0.0 correspond to concentrations below the detection limit; no entry corresponds to cases when the compound was not detected. As seen in the table, for compounds of interest (benz[a]anthracene to indeno[1,2,3-cd]pyrene), there was negligible breakthrough to the downstream tubes. All other tests, except A.4, were conducted at a lower sample airflow rate of $10 \mathrm{~L} / \mathrm{min}$, which would lead to even less breakthrough. For tests A.4 and D.1, the average of all other blank values were used because the sample blanks for these tests were not valid. 


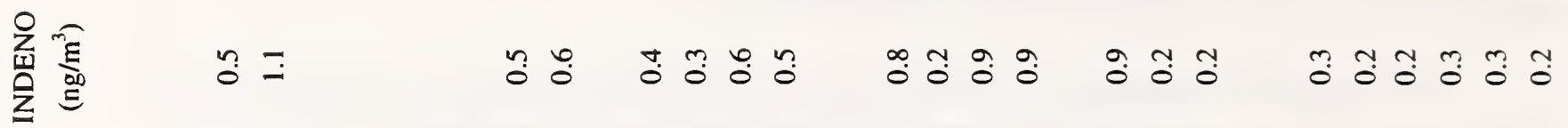

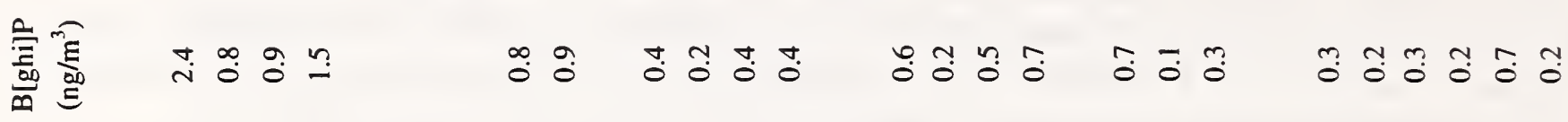

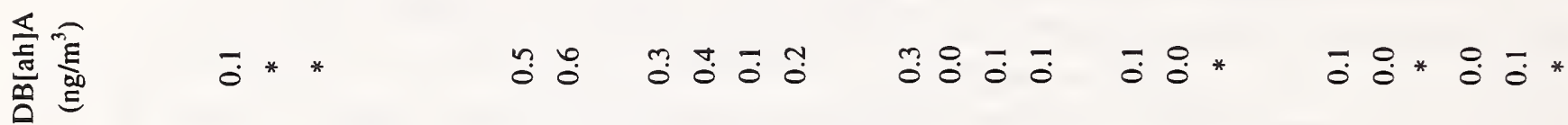



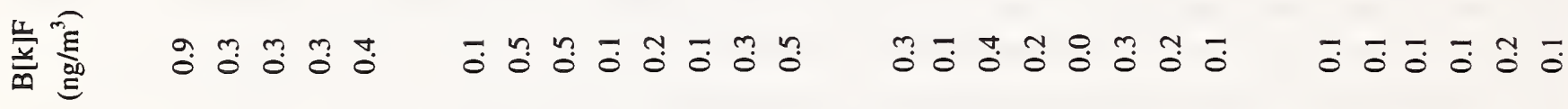

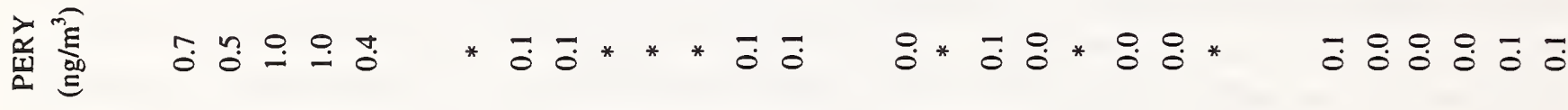



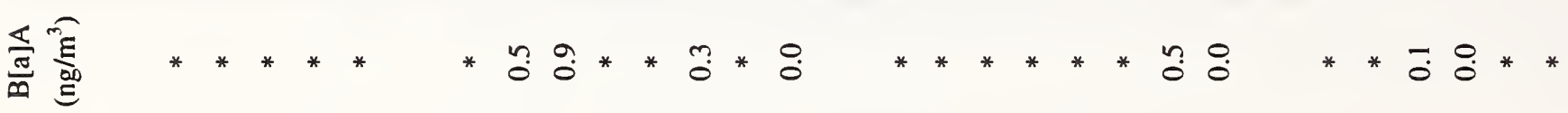

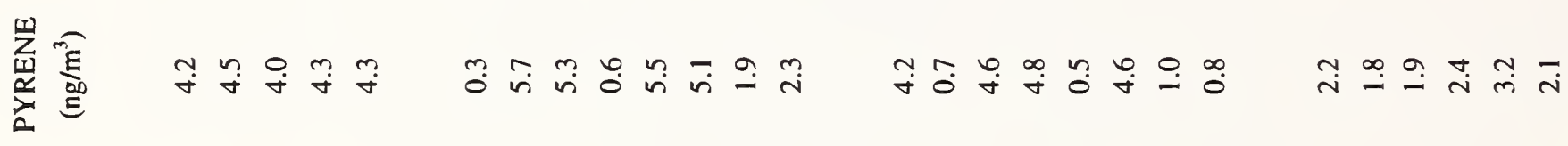

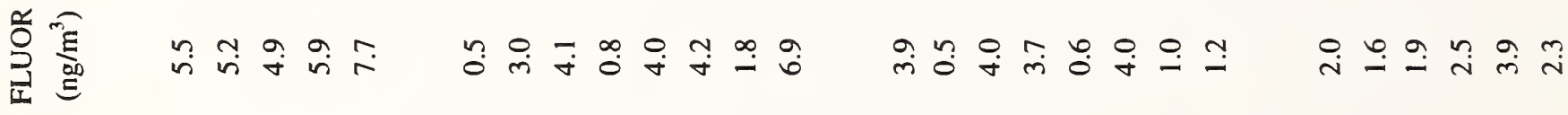



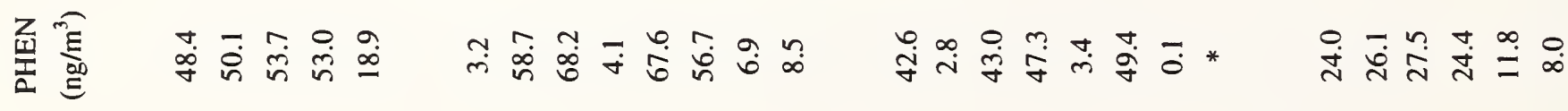



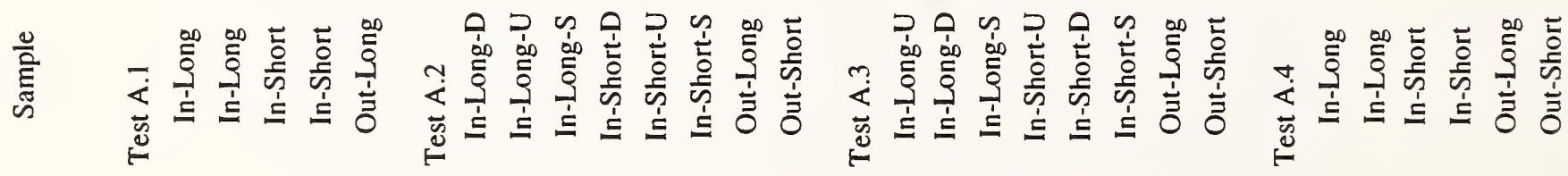






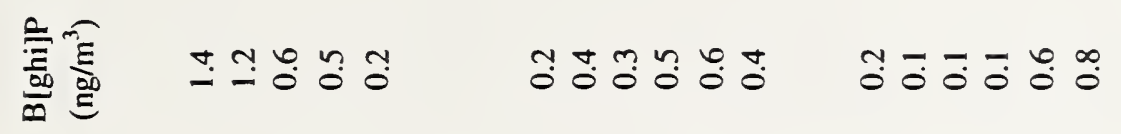



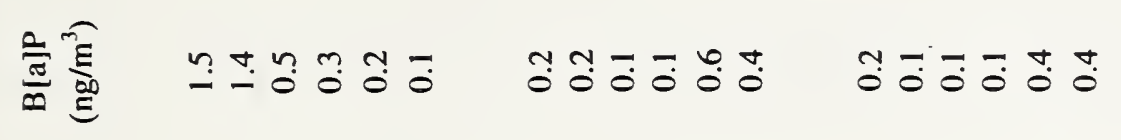

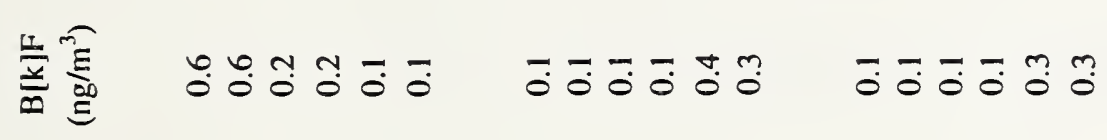

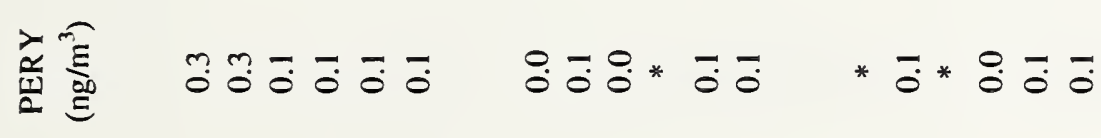

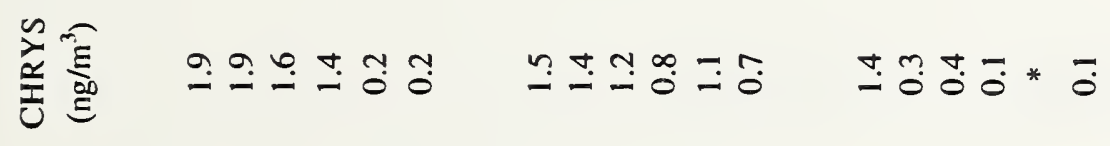
紊爱

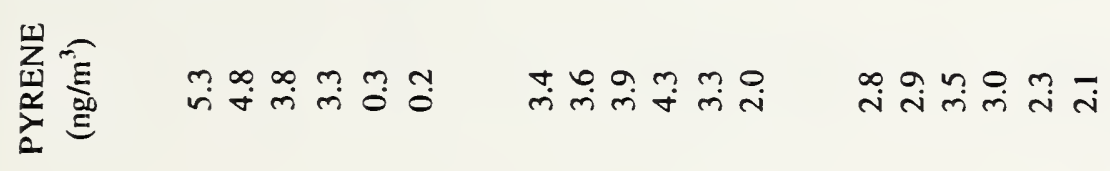

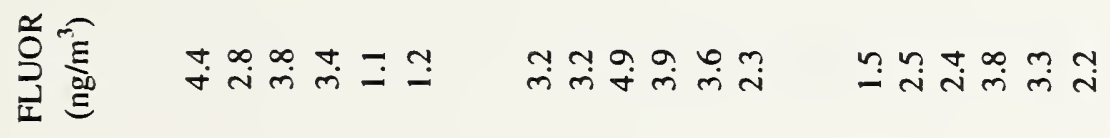



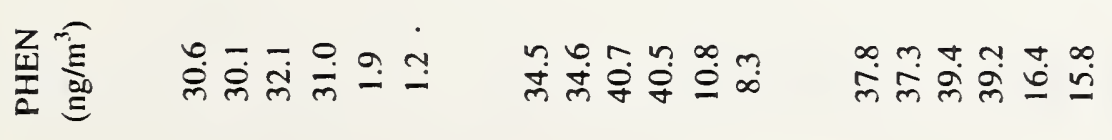

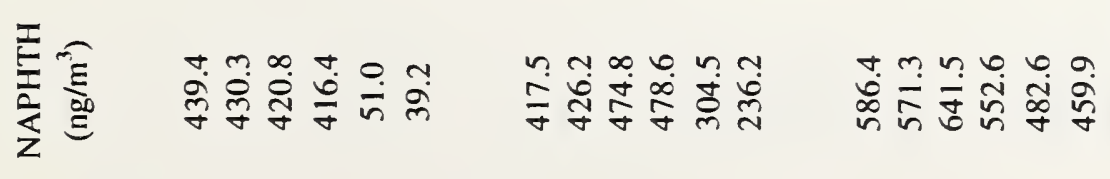






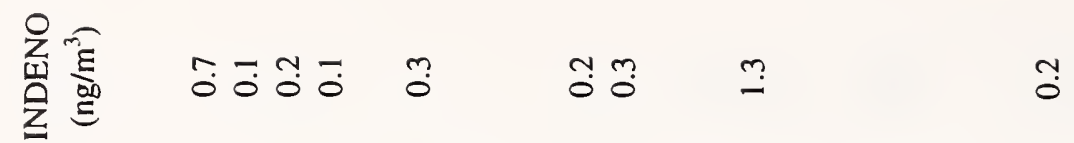

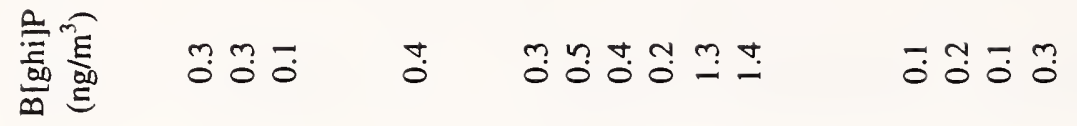

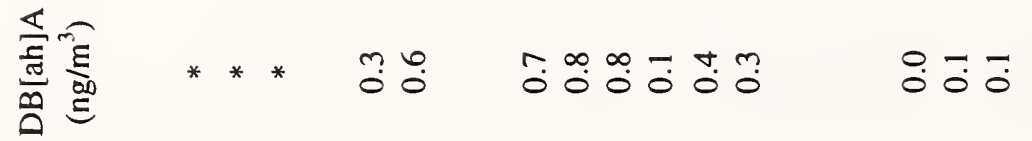



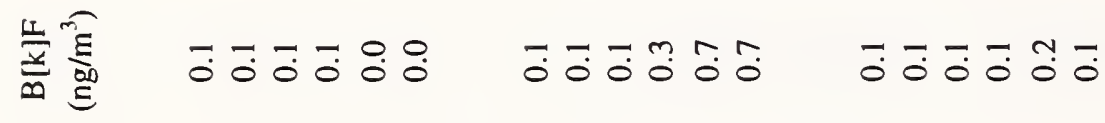

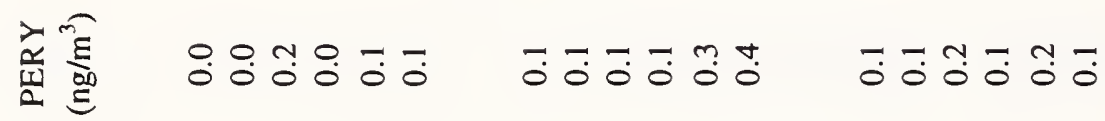

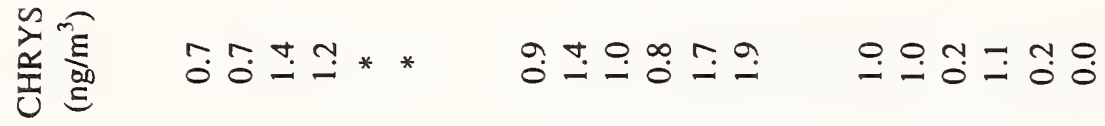

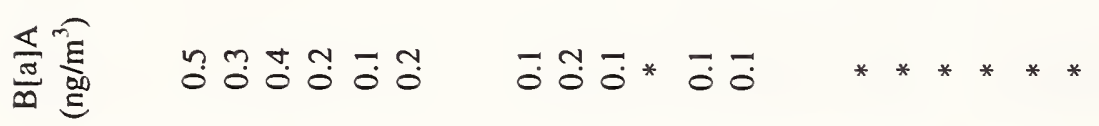

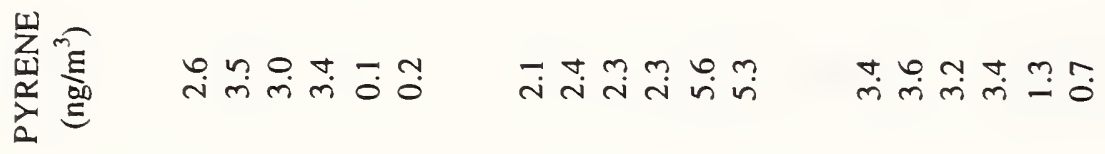

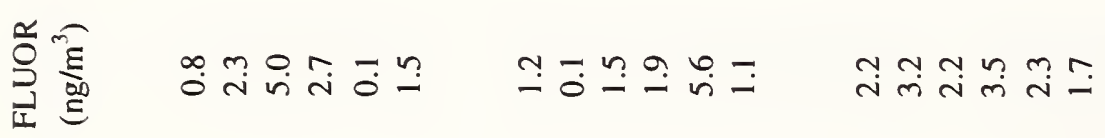

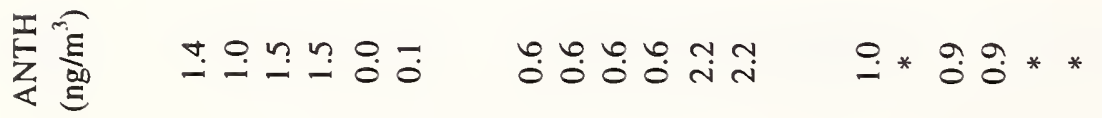



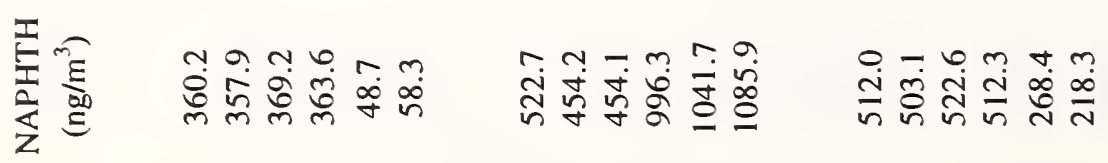






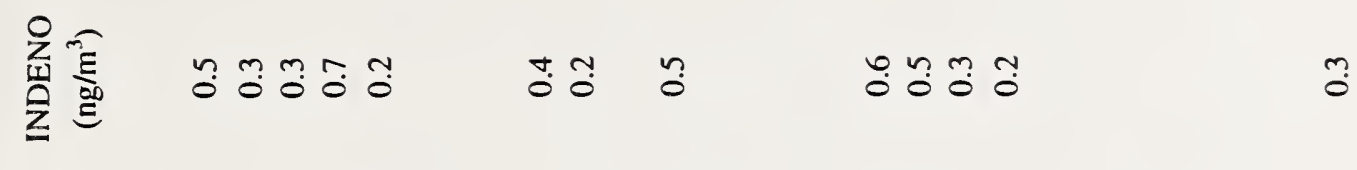

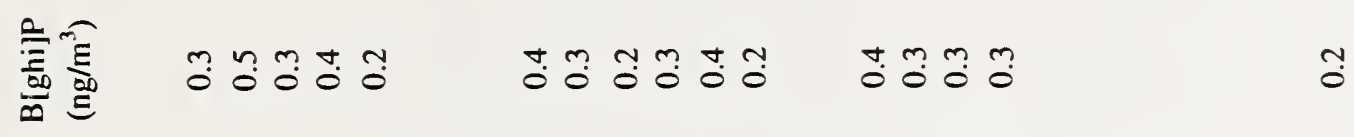

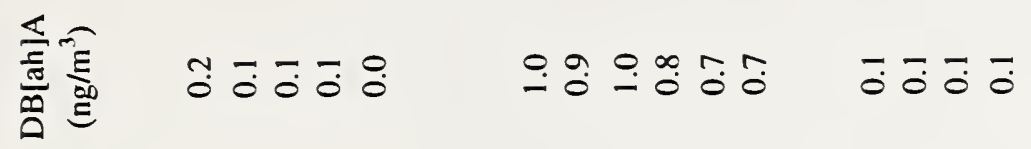



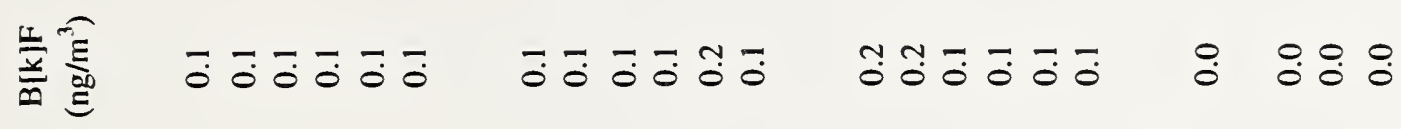

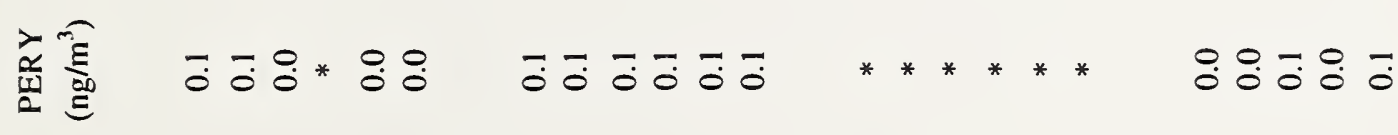

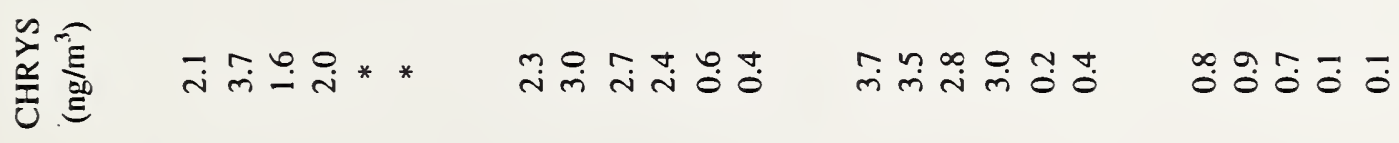

远

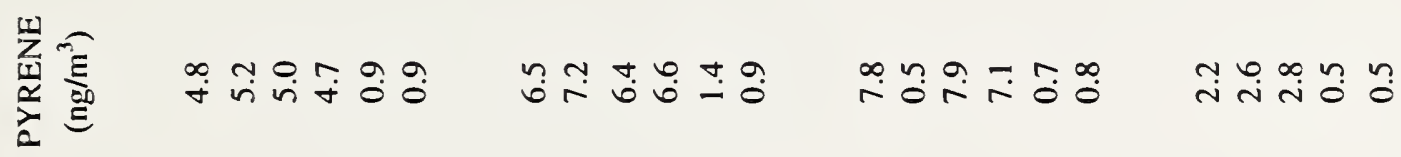

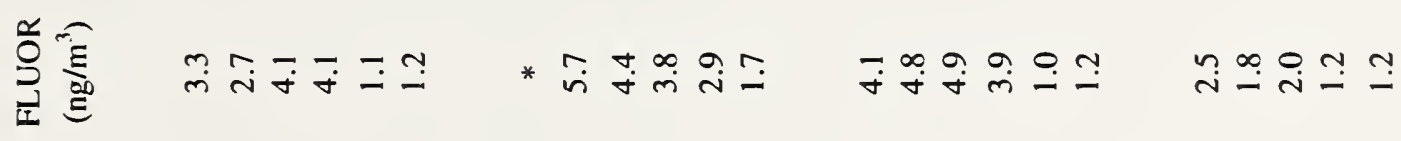

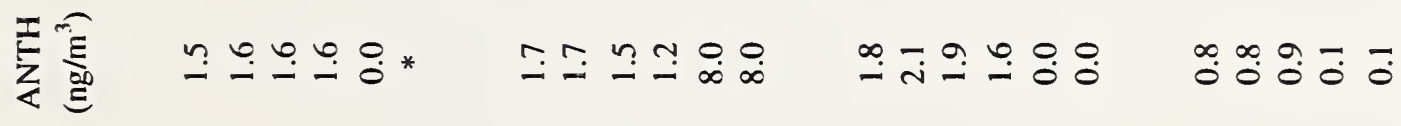



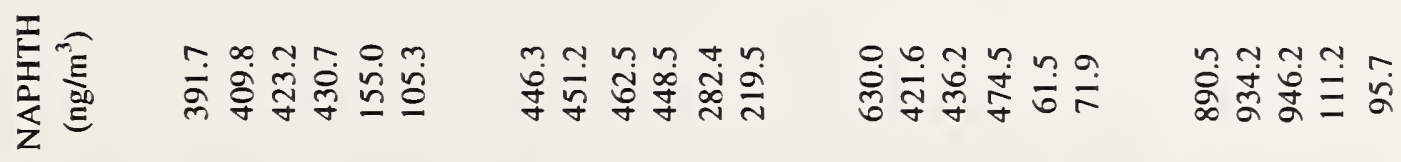

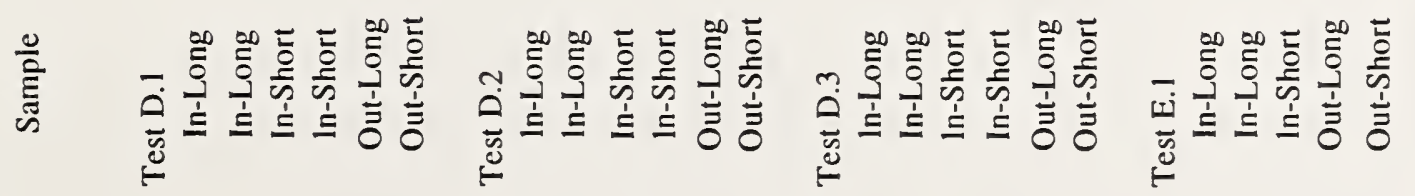



t 